\title{
Endoplasmic Reticulum Stress in Disease Pathogenesis
}

\author{
Jonathan H. Lin ${ }^{1,2}$, Peter Walter ${ }^{1,3}$, and T.S. Benedict Yen ${ }^{2,4}$ \\ Jonathan H. Lin: Jonathan.Lin@ucsf.edu; Peter Walter: walter@cgl.ucsf.edu; T.S. Benedict Yen: yen@itsa.ucsf.edu \\ ${ }^{1}$ Department of Biochemistry and Biophysics, University of California, San Francisco, California \\ 94143 \\ ${ }^{2}$ Department of Pathology, University of California, San Francisco, California 94143; \\ ${ }^{3}$ Howard Hughes Medical Institute, Chevy Chase, Maryland 2081 \\ ${ }^{4}$ Pathology Service, San Francisco Veterans Affairs Medical Center, San Francisco, California \\ 94121
}

\begin{abstract}
The endoplasmic reticulum (ER) is the site of synthesis and folding of membrane and secretory proteins, which, collectively, represent a large fraction of the total protein output of a mammalian cell. Therefore, the protein flux through the ER must be carefully monitored for abnormalities, including the buildup of misfolded proteins. Mammalian cells have evolved an intricate set of signaling pathways from the ER to the cytosol and nucleus, to allow the cell to respond to the presence of misfolded proteins within the ER. These pathways, known collectively as the unfolded protein response, are important for normal cellular homeostasis and organismal development and may also play key roles in the pathogenesis of many diseases. This review provides background information on the unfolded protein response and discusses a selection of diseases whose pathogenesis involves ER stress.
\end{abstract}

\section{Keywords}

protein misfolding; unfolded protein response; IRE1; PERK; ATF-6

\section{Endoplasmic Reticulum Stress and Cytotoxic Signaling from the Unfolded Protein Response}

The endoplasmic reticulum (ER) is a large membrane-enclosed cellular organelle, found in all eukaryotes, that is the site of folding of membrane and secreted proteins, synthesis of lipids and sterols, and storage of free calcium. Physiologic stresses, such as increased secretory load, or pathological stresses, such as the presence of mutated proteins that cannot properly fold in the ER, can lead to an imbalance between the demand for protein folding and the capacity of the ER for protein folding, thereby causing ER stress. To sense and respond to ER stress, eukaryotic cells have evolved a group of signal transduction pathways, collectively termed the unfolded protein response (UPR) (reviewed in Reference 1). The most ER-proximal regulators of the UPR consist of a set of transmembrane ER-resident proteins, including inositol-requiring protein 1 (IRE1), PKR-like endoplasmic reticulum kinase (PERK), and activating transcription factor (ATF)-6. These proteins bear domains protruding into the ER lumen, which sense ER stress, coupled to cytosolic effector domains.

Copyright () 2008 by Annual Reviews. All rights reserved

Disclosure Statement: The authors are not aware of any biases that might be perceived as affecting the objectivity of this review. 
ER stress occurs when the capacity of the ER to fold proteins becomes saturated. ER stress may be caused by factors that impair protein glycosylation or disulfide bond formation, or by overexpression of or mutations in proteins entering the secretory pathway. Ultimately, signaling from these stress-sensing proteins protects the cell or, alternatively, promotes cell death. The role of the UPR in influencing cellular life/death decisions in response to ER stress has led to intense interest in the link between UPR signaling and human diseases that arise from pathologic conditions eliciting ER stress. Here, we first focus on the molecular mechanisms by which UPR signaling pathways promote cell death in response to ER stress. We then discuss how UPR signaling may play a causal role in the pathogenesis of select diseases.

IRE1 governs the most phylogenetically conserved UPR signaling pathway. In mammals, IRE1 $a$ is present in every cell, whereas expression of the related IRE1 $\beta$ is restricted to intestinal epithelial cells. In response to ER stress, IRE1 oligomerizes in the plane of the ER membrane, which in turn activates kinase and endoribonuclease functions present in its cytosolic domain (Figure 1). The cytoprotective output of IRE1 is present across all eukaryotes and is mediated through the specific splicing of $X b p-1$ mRNA, initiated by IRE1's endoribonuclease activity $(2,3,3 \mathrm{a})$. Spliced $X b p-1$ encodes a potent transcription factor of the basic-leucine zipper (B-ZIP) family, whose genetic targets code for proteins that enhance ER protein-folding capacity and degradation of misfolded ER proteins, thereby protecting the cell by specifically reducing the ER stress stimulus $(4,5,150)$.

In higher eukaryotes, IRE1 has acquired additional functions thought to promote cell death in response to ER stress. One proposed proapoptotic output of IRE1 signaling may be its activation of c-Jun N-terminal kinase (JNK) $(6,7)$. In response to ER stress, the kinase domain of IRE1 binds to the TRAF2 adaptor molecule and activates the apoptosis signalregulating kinase 1 (ASK1), which, in turn, causes the phosphorylation and activation of JNK. JNK activation has been demonstrated to trigger cell death in response to TNFa receptor activation or UV irradiation (8). Furthermore, $A s k 1^{-1}$ cells fail to activate JNK and are resistant to apoptosis in response to ER stress (7). These findings suggest that JNK activation by the IRE1/TRAF2/ASK1 complex can contribute to cell death in response to ER stress. However, JNK signaling elicits many cellular responses besides cell death and can even promote cell survival in specific circumstances (8). Similarly, the ASK1 kinase activates signaling pathways besides JNK (9), and the resistance of $A s k 1^{-/}$cells to apoptosis after ER stress could reflect the inactivation of multiple ASK1-dependent downstream processes. Additional studies are needed to clarify the biologic significance of JNK activation by IRE1 after ER stress.

IRE1 signaling may also promote cell death after ER stress by activating caspases, which encompass a large family of cysteine proteases that either relay the death signal or act as the actual effectors of apoptosis. The adaptor molecule, TRAF2, interacts directly with murine procaspase-12, and ER stress disrupts this interaction, possibly by causing the IRE1 kinase domain to bind TRAF2, which in turn leads to the conversion of procaspase-12 into the active enzyme (10). However, the role of caspase-12 in the promotion of cell death after ER stress remains controversial. Although one report showed that murine Caspase-12-1- cells are largely resistant to cell death induced by ER stress (11), another group observed no significant resistance to ER stress when they independently generated Caspase-12-1- cells (12). Furthermore, the human Caspase-12 gene contains an inactivating mutation in most people (13), and thus its product is unlikely to play a key function in human cells. Caspase-4 and caspase-11 have been proposed to promote cell death after ER stress in lieu of or in addition to caspase-12 (14). The link between IRE1 activation and caspases therefore needs further investigation at this time. 
The ability of IRE1 to promote cell death has been largely attributed to signaling via its kinase domain. However, IRE1's endoribonuclease function may also play a role in regulating cell survival in response to ER stress. In human cells, for example, IRE1 was proposed to initiate the endonucleolytic cleavage of its own mRNA as a negative feedback mechanism after ER stress (15). In Drosophila cells, IRE1 activation by the strong reducing agent dithiothreitol triggered the cleavage and ensuing decay of a large set of mRNAs (16). These findings suggest a role for the ribonucleatic function of IRE1 in regulating mRNA targets besides $X b p-1$ after ER stress and raise the possibility that IRE1 could control cell death by downregulating the levels of target mRNAs involved in cell survival. However, because neither study could demonstrate in vitro that IRE1's nuclease directly initiates mRNA breakdown, it remains plausible that IRE1 recruits or activates another cellular ribonuclease to cause mRNA decay after ER stress.

The PERK branch of the UPR also elicits proapoptotic effects after activation. PERK bears an ER-lumenal domain, homologous to that of IRE1, that monitors the protein-folding environment within the ER. Like IRE1, PERK oligomerizes in response to ER stress to activate a kinase function resident in its cytosolic domain (17). The only known target of this kinase activity is the eukaryotic initiation factor $2 a$ (eIF2a), a ubiquitous cofactor required for the assembly of $80 \mathrm{~S}$ ribosomes at the initiation codon of mRNAs to commence protein synthesis (18). Phosphorylation of eIF2a, by kinases such as PERK, inhibits its function $(19,20)$. In turn, protein synthesis in the cell declines as ribosomes fail to assemble efficiently on mRNAs (21). Hence, PERK signaling protects the cell from protein misfolding in the ER by instituting a global slowdown of protein translation. Translational attenuation confers immediate protective advantages, but could also be cytotoxic if protein synthesis dropped below levels necessary to sustain vital functions. To prevent overattenuation of translation, GADD34, a protein phosphatase regulatory subunit, is also induced after ER stress by the PERK pathway and counteracts PERK signaling by promoting the dephosphorylation of eIF2a, thereby restoring ribosomal assembly on mRNAs (22). However, it is unclear how the cell balances the opposing activities of PERK and GADD34 on eIF2a phosphorylation after activation by ER stress to determine whether translational attenuation protects or damages the cell.

For a small group of mRNAs, of which the Atf- 4 mRNA is the best-studied member, PERK activation paradoxically enhances their translation. The Atf-4 mRNA contains multiple upstream open reading frames (uORFs) that precede the $A t f-4 \mathrm{ORF}$ (21). This unusual molecular organization normally suppresses ATF-4 protein synthesis when ribosomal assembly is efficient, as ribosomes initiate translation at the decoy uORFs. However, it enhances ATF-4 translation when ribosomal assembly is impaired during ER stress because the uORFs are bypassed in favor of the ATF-4 start codon. The ATF-4 protein is another BZIP-containing transcription factor, whose targets include ER chaperones and, hence, help alleviate ER stress. However, ATF-4 also promotes apoptosis by increasing transcription of Chop/Gadd153 (23), which encodes yet another transcription factor in the B-ZIP family. $\mathrm{CHOP}$ has an important role in regulating cell death after ER stress, as demonstrated by the resistance of $C h o p^{-/-}$cells to apoptosis in response to a variety of ER stresses. CHOP can cause cell death by increasing the amount of GADD34, which restores translation, and by increasing oxidative stress $(24,25)$, but there may be other mechanisms by which CHOP's transcriptional output promotes cell death, such as by increasing the expression of TRB3 (26).

ATF- $6 a$ governs the third branch of the mammalian UPR and is the archetype of a growing family of transmembrane ER stress sensors that also include ATF-6 $\beta$, OASIS, CREBH, LUMAN, and BBF2H7 (1, 27-31). In contrast to the ubiquitous expression of IRE1a and PERK, many of these stress transducers are expressed in a cell-type- or tissue-specific 
manner (28). ATF-6a bears an ER luminal stress-sensing domain coupled via a transmembrane segment to a cytosolic B-ZIP transcription factor domain (32). In response to ER stress, ATF-6a traffics from the ER to the Golgi, where specific proteases cleave the transmembrane domain and liberate the cytosolic portion of ATF-6a (33). This severed fragment then translocates to the nucleus, where it acts as a transcription factor to upregulate UPR target genes that overlap with those activated by XBP-1 and ATF-4. In this manner, ATF-6a is thought to protect the cell from ER stress (34). Some reports, however, suggest that ATF-6a may also have a proapoptotic function. When a myoblast cell line was induced to differentiate, ATF-6a activation was selectively observed in cells destined to die, and inhibition of ATF-6a processing enhanced cell survival (35). In a macrophage cell line, ATF- $6 a$ activity was activated during cell death induced by lipopolysaccharide and interferon- $\gamma$, and expression of a dominant negative form of ATF- $6 a$ ameliorated cell death induced by those agents (36). However, the methods used to block ATF-6a activation in these studies were not specific and likely affected other B-ZIP proteins cleaved by the Golgi proteases that process ATF-6a.

BAK and BAX are members of the BCL-2 protein family that regulate apoptosis by a mechanism thought to involve their multimerization and insertion into the mitochondria, thereby facilitating the exit of cytochrome $c$ into the cytosol to initiate apoptosis (37). $\mathrm{Bak}^{-1-} \mathrm{Bax}^{-1-}$ cells are highly resistant to cell death induced by a wide variety of stimuli, including agents that cause ER stress (38). BAK and BAX are also present at the ER membrane, and another proposed mechanism by which they promote cell death involves the release of ER luminal calcium to activate cell death pathways by releasing cytochrome $c$ from the mitochondria (39-41). An alternative and not incompatible possibility is that BAK and BAX at the ER can directly activate apoptotic pathways without involving mitochondria (40). It is not obvious how BAK and BAX would detect ER stress, as they bear no molecular or functional homology to the ER stress-sensing domains of the canonical UPR regulators, IRE1, PERK, and ATF-6a. One possible solution to this question would involve an interaction of one of the known ER stress sensors with BAK and BAX. Indeed, a recent report indicated that IRE1a at the ER may need BAK and BAX to control cellular responses after ER stress (42). Through the use of biochemical and genetic approaches in $\mathrm{Bak}^{-1-} \mathrm{Bax}^{-1-}$ cells, defects in IREla branch signaling were identified that were proposed to arise from the loss of stabilizing interactions between IRE1a, BAK, and BAX at the ER membrane. These findings raise the possibility that, upon ER stress, IRE1a may in turn activate BAK and BAX to mediate cell death.

How does the mammalian UPR integrate its protective and toxic outputs elicited by ER stress to determine life or death cell fates? No source of ER stress that activates only cytoprotective or proapoptotic outputs from UPR signaling pathways has been found. Instead, all known ER stressors trigger the entire UPR, thereby initiating both protective and proapoptotic outputs simultaneously. One model that reconciles how the concomitant production of cytoprotective and proapoptotic outputs from the UPR leads to survival or death posits the selective temporal regulation of UPR branch signaling pathways after ER stress (Figure 1). In this model, IRE1a, PERK, and ATF-6a are all initially activated. Their combined actions would provide protective outputs such as reduced translation, enhanced ER protein-folding capacity, and clearance of misfolded ER proteins, in addition to proapoptotic outputs such as CHOP production. Protective outputs would initially outweigh proapoptotic factors, perhaps in part because prosurvival UPR effector molecules such as GRP78 (BiP) are significantly more stable, both at the mRNA and protein levels, than antisurvival factors (43). This phase of predominantly protective UPR output would therefore provide a window of opportunity whereby the cell could try to adapt to ER stress, such as by increasing chaperone levels to facilitate protein folding or increasing ERassociated protein degradation to remove terminally misfolded proteins. 
Should these steps fail to reduce ER stress, which would occur with the application of lethal doses of ER toxins or prolonged production of terminally misfolded proteins, protective outputs would be reduced. Indeed, attenuation of the entire IRE1 branch of the UPR and an ensuing decline in chaperone production are observed in human cells with unresolved ER stress (43a). With loss of protective outputs, unchecked UPR proapoptotic signaling would guide the cell toward its demise and also sensitize it to any further deleterious insults that might occur, such as hypoxia or nutrient starvation. Elucidating the behavior and regulation of the individual UPR signaling pathways after ER stress will be important for understanding how the protective and proapoptotic outputs of the UPR are used to determine cell survival or death, and will likely provide a molecular framework in which to understand the pathogenesis of diseases linked to protein misfolding and ER dysfunction, as well as to guide the design of pharmaceutical agents to ameliorate or cure these diseases.

\section{Endoplasmic Reticulum Stress and Disease Pathogenesis}

As ER stress and the attendant UPR can lead to cell death, it is not surprising that conditions that lead to an increase in protein misfolding or a decrease in the ability of the cell to handle these proteins in the ER can result in cellular dysfunction and disease. Such diseases may result from the decreased ability of the cell to fold secreted or membrane proteins, the decreased ability to recognize or respond to misfolded proteins, and/or the increased load of misfolded proteins. Inappropriate activation of the UPR may also be harmful, by killing the cell or even by protecting the cell from death (e.g., during neoplastic transformation or viral infection). Indeed, each of these situations, either naturally occurring or experimentally induced, has been shown to cause cellular and/or organismal injury in human beings or in model organisms. Selected examples are discussed in detail in the following sections to illustrate the possible role of ER stress in pathogenesis, the UPR pathways proposed to be involved, and potential therapeutic avenues.

\section{Diabetes Mellitus}

Diabetes mellitus (DM) results from insufficient insulin function to maintain homeostasis of glucose metabolism. In type IDM, there is a primary failure of the pancreatic islet $\beta$ cells to secrete sufficient amounts of insulin. In many patients, this defect results from an autoimmune attack on the $\beta$ cells. In rare cases, $\beta$ cell failure and/or death is inherited as a mono-genetic disease. In type II DM, the pathology first arises in the peripheral tissues, in the form of insulin resistance, that is, a failure to respond appropriately to normal levels of insulin. To compensate, the $\beta$ cells hypersecrete insulin and may eventually die. As the $\beta$ cells constitute a type of professional secretory cell, it is not surprising that ER stress and the UPR have been implicated in $\beta$ cell dysfunction and apoptosis in certain hereditary forms of DM as well as in $\beta$ cell exhaustion late in the course of type II DM. More unexpectedly, however, ER stress has also been implicated in earlier stages of type II DM, at a time of endorgan insulin resistance rather than of failure of insulin secretion, as well as in immunemediated type I DM.

One form of human hereditary DM, the Wollcott-Rallison syndrome, is caused by presumed inactivating mutations in the Perk gene (44). Similarly, Perk knockout mice also develop diabetes (45). In both species, there is progressive loss of $\beta$ cells during postnatal development, presumably as a result of apoptosis downstream of ER stress. It is likely that the absence of PERK results in the inability of the $\beta$ cell to decrease the load of proteins entering the ER during periods when the folding capacity of the ER has been exceeded because of especially high demand for insulin synthesis and secretion. In agreement with this interpretation, mice engineered to have a non-phosphorylable form of eIF2 $a$ also develop diabetes (46), as PERK decreases the load on the ER by inactivating eIF2 $a$ via 
phosphorylation. Interestingly, these eIF2a mutant mice develop diabetes earlier than Perk knockout mice, suggesting that the basal level of phosphorylation mediated by other eIF2a kinases partially protects the $\beta$ cell from ER stress. However, a recent paper showed that PERK is required only during development, and adult mice do not require PERK to remain nondiabetic (47). Thus, PERK may play a more important role for $\beta$ cell differentiation than for their survival. It is not known whether there may be more ER stress in the $\beta$ cell during development than in adult life, or if PERK may also be important for a survival pathway separate from the UPR. Notably, PERK deficiency causes endocrine pancreatic dysfunction, but has no apparent adverse effect on other tissues with high protein flux through the ER, such as the liver and plasma cells (45). Conversely, mice with knockout of the $X b p-1$ gene fail to develop normal exocrine pancreas, hepatocytes, plasma cells, and salivary glands, but show no prenatal defect in pancreatic islet development, although postnatal development could not be examined because of perinatal lethality (48). Therefore, clearly there are differences in the importance of the various branches of the UPR for different types of secretory cells. One possible explanation is that there are cell-type-specific UPR pathways and/or targets thereof. Indeed, the product of the $w f s 1$ gene, which is mutated in people with Wolfram's syndrome (another form of hereditary DM) $(49,50)$, is a PERK-responsive protein that is mostly expressed in $\beta$ cells in the pancreas $(51,52)$. Targeted knockout of $w f s 1$ in $\beta$ cells results in ER stress and apoptosis of these cells $(53,54)$. Thus, it is likely that the lack of PERK causes $\beta$ cell loss at least in part by the failure to upregulate $w f s$. It would be important to determine if loss of eIF2a phosphorylation also leads to decreased $w f s 1$ expression, and if the forced expression of WFS1 can at least partially rescue DM caused by the loss of eIF $2 a$ phosphorylation. In any case, additional studies are needed to understand the pathways operating in $\beta$ cell development and function both upstream and downstream of PERK, for example, by using tissue-specific gene knockouts at specific stages in development.

An inherited defect in insulin itself can also lead to DM via ER stress in mice. The so-called Akita mice contain a missense mutation in the insulin 2 gene (55). Both heterozygous and homozygous mice develop DM early in life. Clearly, DM does not result from an insufficient amount of circulating insulin, as mice have two loci for insulin and knocking out both copies of the insulin 2 gene does not lead to a diabetic phenotype (56). Rather, the mutant insulin synthesized by the Akita mice is misfolded and retained in the ER, leading to ER stress and subsequent $\beta$ cell injury and apoptosis (57). Further support for a role of ER stress in disease pathogenesis comes from the observation that knocking out CHOP expression delayed the onset of diabetes in mice heterozygous for the insulin 2 mutation (57). Although no evidence exists to suggest that mutations in the coding region of the insulin gene play a role in human diabetes, the Akita mouse confirms that ER stress can be an important cause of $\beta$ cell loss.

Type I DM in people is frequently caused by an autoimmune reaction against $\beta$ cells. ER stress has been implicated in this form of DM as well. Cytokines and nitric oxide released by the inflammatory cells have been shown to activate the UPR, presumably by inducing ER stress $(58,59)$. However, no experimental manipulations of the UPR have been performed in model organisms, and thus it is not clear whether the ER stress in this situation is relevant for disease pathogenesis.

There is also evidence that ER stress within $\beta$ cells plays a role in type II DM. ER stress has been found in the $\beta$ cells of the congenitally obese $d b / d b$ mice and of human patients with type II DM (60). This is perhaps due to long-term increased secretion demand to overcome end-organ insulin resistance, although chronic hyperglycemia itself (61), as well as free fatty acids (62), has also been shown to directly induce the UPR in $\beta$ cells. In support of a mechanistic role for ER stress in type II DM, mice heterozygous for nonphosphorylable 
eIF2a show an increased propensity to develop obesity-induced DM (63). These data can be explained by the dysfunction or death of $\beta$ cells owing to ER stress caused by the increased demand for insulin secretion in the setting of obesity-induced insulin resistance. However, the interpretation of the data is complicated by the recent revelation of a relationship between ER stress and insulin resistance in the target organs of insulin (i.e., liver, adipose tissue, and skeletal muscle). Two parallel sets of experiments were performed in two different mouse models of obesity and insulin resistance. First, Özcan et al. (64) showed that obesity induces ER stress in the liver, which then leads to the inhibition of insulin signaling by the phosphorylation of insulin receptor substrate1 via activation ofIRE1 and JNK, although other pathways, such as one involving the inhibition of AKT by the CHOP-induced protein TRB3 (65), may also be important. Treatment of leptin-deficient $o b / o b$ mice with small molecules that act as chaperones for the proper folding of secretory proteins resulted in the resolution of ER stress in the liver, normalization of blood glucose levels, restoration of insulin sensitivity, and loss of steatosis (66). Remarkably, these chaperones both suppressed hepatic glucose output and increased glucose disposal in peripheral tissues, presumably skeletal muscle and adipose tissue. Similarly, Nakatani et al. (67) showed that the obese $d b / d b$ mice also suffered from ER stress in the liver. The liver-specific overexpression of a single ER chaperone protein that helps to relieve ER stress, the oxygenregulated protein 150 (ORP150), resulted in marked improvement of glucose tolerance and insulin sensitivity, whereas decreasing the expression of ORP150 in the liver of genetically normal mice resulted in decreased insulin sensitivity (67). These latter studies confirm the importance of ER stress in causing insulin resistance and reveal that it is the relief of ER stress in target tissues rather than in the $\beta$ cells that leads to amelioration of diabetes in these model organisms. In a similar vein, mice with heterozygous knockout of the $x b p-1$ gene show insulin resistance (64). Thus, it will be important to determine whether heterozygous defects in the eIF2a pathway increase the risk of type II DM via effects in $\beta$ cells, target organs, or both. Mice with tissue-specific knockout of the various genes involved in UPR will again be extremely useful in this regard. Consistent with a role for ER stress and the UPR in the development of insulin resistance, ATF-6a polymorphisms have been linked to type II DM in both Pima Indians and Dutch Caucasians (67a, 67b).

The mechanism by which obesity can induce ER stress in peripheral tissues is still unclear, although free fatty acids may be involved (68). Regardless, in view of the potential importance of ER stress for multiple stages and organs of type II DM, the systemic administration of small-molecule chaperones that help alleviate ER stress can potentially be triply beneficial in this common and devastating disease: by decreasing glucose output from the liver, by increasing glucose utilization by peripheral tissues, and by preventing the loss of $\beta$ cells as a result of ER stress caused by increased demand and/or hyperglycemia. However, it is notable that $\beta$ cell survival under conditions of ER stress is improved by the expression of ATF-4, a downstream target of PERK, probably by leading to the expression of antioxidant genes that help counter oxidative stress caused by accumulation of proteins in the ER (69). Similarly, treatment of $d b / d b$ mice with exendin-4, a molecule that binds to glucagon-like-peptide receptor 1 and increases ATF-4 expression via cyclic AMP, improves DM in these obese mice (70). Therefore, partial relief of ER stress, which may prevent the synthesis of ATF-4 without clearing all of the accumulated ER proteins or blocking other downstream effectors of the UPR, could paradoxically increase the death of $\beta$ cells. Such an effect would not be surprising, in light of the dual protective and proapoptotic effects that the UPR exerts on the cell. For example, transient phosphorylation of eIF2a protects cells against apoptosis caused by ER stress (71), yet CHOP, a transcription factor downstream of eIF2a phosphorylation, causes cell death, possibly by increasing the ER protein load and oxidative stress (25). Clearly, more detailed analysis of each different kind of tissue over long periods of treatment in various model organisms will be necessary to determine the usefulness of various chemical chaperones as well as the appropriate therapeutic dosages. 


\section{Viral Infections}

Because enveloped viruses must utilize a large amount of membrane proteins and lipids for their morphogenesis (Figure 2), and because even many nonenveloped viruses depend upon intracellular membranes for their replication and/or morphogenesis, it is not surprising that a variety of unrelated viruses have been found to induce ER stress and the UPR, as well as manipulate the UPR. However, as in other diseases, the interplay between each virus and the host UPR is complex and as yet incompletely understood. The PERK pathway of the UPR may well function as a host antiviral defense, as this kinase is homologous to and has similar kinase activity as the double-stranded RNA-activated protein kinase PKR, which is known to be part of the cellular antiviral armamentarium. Indeed, Baltzis et al. (72) showed that fibroblasts deficient in PERK support much higher levels of vesicular stomatitis virus replication than wild-type fibroblasts. There is a corresponding increase in apoptosis of the host cells, although it is not clear whether the cell death resulted from the inability of the ER to respond to the increased load of the viral infection or from some other cytopathic effect of the higher cellular viral load. Unexpectedly, PKR activation is also partially defective in the cells, suggesting a hitherto unsuspected cross talk between these two kinases. Other studies have similarly shown that blocking the phosphorylation of eIF2a leads to increased vesicular stomatitis virus replication and cytopathic effects (73), confirming that PERK exerts its antiviral effects via a translational block.

If PERK-mediated eIF2a phosphorylation is an important cellular mechanism for controlling viral replication, then viruses may have evolved mechanisms to counter this pathway. One possible example is provided by the herpes simplex virus (HSV) type I. This virus encodes a protein known as ICP34.5, which is homologous to the cellular protein GADD34 that mediates the dephosphorylation of eIF2a (74). ICP34.5 is important for HSV replication in certain cell types (74). Importantly, the absence of ICP34.5 decreases the ability of the virus to grow and spread in the host organism (75), and salubrinal, a small molecule that blocks the dephosphorylation of eIF2a, decreases HSV replication in murine cornea (76). These data are consistent with eIF2a phosphorylation having antiviral effects. Similarly, the African swine fever virus, despite being an enveloped virus, does not cause eIF2a phosphorylation in infected cells (77). This lack of a response appears to be due to a specific block in the UPR, as infected cells also do not respond to chemical inducers of ER stress. The viral factor responsible for this effect may be DP71L, which shows homology to HSV ICP34.5 protein and can also associate with the enzyme that dephosphorylates eIF2a (78), although a direct role for this protein in decreasing eIF2a phosphorylation or in facilitating viral replication has not yet been proven. Note that because both PERK and PKR induce eIF2a phosphorylation, it is not clear whether the PERK pathway is actually the main activator of eIF2a that is targeted byICP34.5, DP71L, and similar viral proteins. However, specific inhibition of PERK by both hepatitis C virus (HCV) (79) and HSV (80) has been demonstrated. Remarkably, for both viruses the proteins responsible for this function are viral envelope glycoproteins: $\mathrm{E} 2$ for $\mathrm{HCV}$ and $\mathrm{gB}$ for $\mathrm{HSV}$. These proteins were expected to induce ER stress, and indeed the HCV E2 protein does induce ER stress, as measured by the induction of GRP78, when expressed at low levels $(79,81)$. Thus, these viruses appear to have adapted inducers of ER stress to be inhibitors of ER stress instead. Unfortunately, both $\mathrm{E} 2$ and $\mathrm{gB}$ are essential structural components of the respective viruses, and hence it cannot be determined whether deletion of these proteins leads to decreased virus production. In any case, this function of $\mathrm{E} 2$ and $\mathrm{gB}$ lends further credence to the theory that at least the PERK pathway of the UPR has antiviral functions.

Other branches of the UPR may also function as antiviral host defenses, as some viruses appear to manipulate them. For example, human cytomegalovirus (82) and HCV (83) both induce ER stress, as suggested by the splicing of $X b p-1$ mRNA, yet do not show induction 
of XBP-1-dependent transcription, for example, of the gene Edem. This specific blockage may be tied to the fact that some of the genes activatedbyXBP-1 code for proteins involved in ER-associated protein degradation (84). Thus, activation of this pathway may lead to the undesired loss of ER proteins, viral or cellular, necessary for viral replication and/or morphogenesis.

However, ER stress and the UPR have been implicated not in protection from viral infection but rather in aiding viral replication. It has been postulated that the cytomegalovirus US11 protein activates the UPR to increase the degradation of class I major histocompatibility complex proteins (85), resulting in an escape from the host immune response. For the reovirus, strains that induce eIF2a phosphorylation replicate better, apparently because of increased ATF-4 expression as well as the sequestration of competing host mRNA molecules in so-called stress granules that contain nontranslated messages (86). The hepatitis B virus (HBV) even has a promoter that is upregulated by ER stress (87). Thus, it is likely that some viruses have evolved mechanisms to escape the negative consequences of ER stress and simultaneously use selected subsets of factors induced by the UPR for their own advantage.

Finally, ER stress may be involved in viropathic effects and hence diseases caused by viruses. Some murine retroviruses cause spongiform encephalopathy with neurodegeneration and gliosis. Interestingly, two such viruses have been shown to cause ER stress in the brain $(88,89)$. By using isogenic viruses different only in their envelope proteins, it is clear that both ER stress and disease manifestation in the case of the retrovirus $\mathrm{FrCas}^{\mathrm{E}}$ are linked to the envelope protein (90). The unrelated Borna disease virus also induces ER stress and subsequent neuronal injury in the hippocampus (91), although the viral protein that causes ER stress has not been identified.

In the examples cited above, it is actually the glial cells that are infected by the virus and undergo ER stress. Therefore, neuronal injury and death are a secondary phenomenon, either because of the lack of glial cell support or the secretion of toxic cytokines by the injured glial cells and/or inflammatory cells. Direct injury of the infected cells via ER stress has been implicated in other viral diseases. In the cerebellum of mice infected by Borna disease virus, the neuronal Purkinje cells are infected by the virus, show ER stress, and die (91), but a direct relationship between ER stress and neuropathy has not been proven. Similarly, a cytopathic strain of the pestivirus, bovine viral diarrheal virus, induces ER stress, although a strict correlation between cytopathicity and the ability to cause ER stress has not been shown (92). However, it has been demonstrated that the flavivirus Japanese encephalitis virus causes ER stress only in those cell types that show strong cytopathic effects (93), consistent with the notion that ER stress is a mediator of at least part of the cytopathic effects. The final example comes from HBV. HBV is normally noncytopathic and liver injury during infection is believed to be due to attack by the host immune cells. However, in highly immunodeficient hosts, either human or murine, the virus can replicate to extremely high levels and become apparently cytopathic $(94,95)$. In patients with this so-called fibrosing cholestatic hepatitis, one of the HBV envelope proteins (large surface protein) accumulates, resulting in the retention of viral lipoprotein particles in the ER-Golgi intermediate compartment, ballooning of the ER, and apoptosis (96). These findings have been replicated in cultured cells and in transgenic mice expressing only the large surface protein (97; Z.M. Huang \& T.S.B. Yen, unpublished data) (Figure 3). Furthermore, large surface protein alone has also been shown to induce ER stress, both in transgenic mice and cultured cells (98; Z.M. Huang \& T.S.B. Yen, unpublished data). In contrast, expression of normal amounts of large surface protein in conjunction with the other forms of the surface protein does not lead to cellular injury. Therefore, it is highly likely that fibrosing cholestatic hepatitis is an ER stress disease owing to abnormal expression of a viral envelope protein, 
and small molecules that assist in protein folding may be therapeutically useful in ameliorating disease manifestation. However, in view of the possible antiviral functions of PERK and other branches of the UPR, it is possible that such treatment may lead to increased viral production from infected cells and be counterproductive.

\section{Neurodegeneration}

Retinitis pigmentosa (RP) is the most common cause of inherited retinal degeneration and is due to the progressive loss of the specialized rod photoreceptor neurons in the eye (99), which sense light and transmit that information to the brain. To detect light, photoreceptors constitutively manufacture rhodopsin, a light-sensitive chromophore, which can compriseupto30\%ofall proteins in the photoreceptor cell. Rhodopsin consists of the 348 amino acid transmembrane apoprotein opsin, covalently coupled to the light-sensitive smallmolecule 11-cis-retinal. Opsin protein folding occurs in the ER where the nascent polypeptide undergoes disulfide bond formation and glycosylation modifications required for a stable functional conformation. Once properly folded, opsin exits the ER and is transported to the rod photoreceptor outer segment where it covalently binds 11-cis-retinal at a lysine residue, to form rhodopsin. When light strikes rhodopsin, 11-cis-retinal isomerizes to 11-trans-retinal. In this light-activated state, rhodopsin initiates a biochemical signal transduction cascade that leads to the generation of an electrical signal and activation of the visual neural circuitry.

Most cases of RP are due to mutations in the opsin gene. Over 100 distinct mutations in rhodopsin have been identified that lead to retinal degeneration, and the most common rhodopsin mutation leading to autosomal dominant RP in the United States is a proline-tohistidine substitution at position $23(\mathrm{P} 23 \mathrm{H})$ of opsin (100). The biochemical and cellular consequences of the $\mathrm{P} 23 \mathrm{H}$ mutation on rhodopsin maturation and function have been extensively studied and indicate that P23H-rhodopsin is misfolded in the ER (101-103). Compared with the wild-type protein, $\mathrm{P} 23 \mathrm{H}$-rhodopsin displays abnormal sensitivity to trypsin; P23H-rhodopsin is underglycosylated; P23H-rhodopsinisfound associated with ERresident chaperones; and $\mathrm{P} 23 \mathrm{H}$-rhodopsin is localized primarily in the ER/Golgi, whereas wild-type rhodopsin is found at the surface membrane. In vitro, P23H-rhodopsin fails to bind 11-cis-retinal and cannot act as a functional light sensor. Photoreceptors expressing $\mathrm{P} 23 \mathrm{H}-$-rhodopsin eventually die through a poorly understood mechanism. However, a recent study demonstrated that $\mathrm{P} 23 \mathrm{H}$-rhodopsin expression in Drosophila triggered robust $\mathrm{Xbp}-1$ mRNA splicing (104). Cumulatively, these findings provide cellular and genetic evidence that misfolded P23H-rhodopsin causes ER stress and implicate UPR signaling in causing the retinal neurodegeneration that arises from rhodopsin misfolding in autosomal dominant RP.

Alzheimer's disease (AD) is characterized by selective neuronal loss in the hippocampus and basal forebrain. Abnormal protein aggregates consisting of plaques and tangles are pathognomonic features of $\mathrm{AD}$ (105). Several postmortem studies of primary human $\mathrm{AD}$ brain tissues have provided evidence of ER stress in the form of enhanced ER chaperone expression and immunohistochemical reactivity for specific markers of the UPR branch activity $(106,107)$. However, because the aggregated proteins (tangles and plaques) in AD are not found within the ER, these findings raise the question of the source of ER stress that activates UPR signaling in this disease.

$\beta$-amyloid $(\mathrm{A} \beta)$ is a key misfolded polypeptide found in $\mathrm{AD}$ plaques and arises from the proteolytic processing of the trans-membrane $\beta$-amyloid precursor protein ( $\beta$-APP) during its maturation in the secretory pathway (108). Neurotoxicity of $A \beta$ has been demonstrated in experimental systems and has been proposed to underlie, at least in part, the pathologic changes observed in AD (109). The signaling pathways that mediate cytotoxicity in response 
to $A \beta$ are an area of intense interest, and several reports have implicated the UPR in the cytotoxicity of $A \beta$. In cell culture, $A \beta$ expression increased ER chaperone levels and activated caspase-12 (110), and knockdown of caspase-4 or knockout of caspase-12 conferred resistance to A $\beta$-mediated cytotoxicity $(11,14)$. Cultured $A s k 1^{-1-}$ neurons were resistant to $A \beta$ cytotoxicity (111), thereby implicating the IRE1-ASK1-JNK pathway in A $\beta$ mediated cell death. Interestingly, expression of A $\beta$ in rat PC12 cells selectively activated ASK1 and JNK signaling without inducing other outputs of IRE1a and PERK branch signaling (111). Taken together, these findings raise the possibility that $A \beta$ may selectively employ discrete components of the UPR signaling apparatus in mediating cytotoxicity in neurons. However, expression of wild-type $\beta$-APP but not mutant amyloidogenic $\beta$-APP protected cells from ER-stress-induced apoptosis $(112,113)$, raising the possibility that disease actually results from the loss of a protective function of $\beta$-APP against the basal level of ER stress faced by neurons.

ER stress and UPR activation may also arise in AD linked to defective presenilin function. Presenilins are ER-resident membrane proteins that have been best studied for their role as the catalytic subunit of the $\gamma$-secretase enzymatic complex involved in the proteolysis of $\beta$ APP to generate A $\beta$ (114). Presenilins have also been assigned a second independent function in which they act as ion channels that allow exit of calcium from the ER lumen (115). Numerous mutations have been identified in presenilins that cause familial forms of AD (FAD) (116). These mutations impair the ability of presenilin to form ion channels in vitro, and ER luminal calcium levels are significantly elevated in cells expressing FADassociated presenilins compared with wild-type presenilin $(115,117,118)$. It is well known that pharmacologic disruption of ER calcium homeostasis activates UPR signaling pathways. Typically, these agents cause ER stress by depleting the ER luminal calcium pool, such as occurs when thapsigargin binds the smooth ER calcium AT Pase and inhibits calcium uptake from the cytosol (119). It is less clear how ER calcium overloading induced by presenilin dysfunction affects the protein-folding environment of the ER and activity of the UPR. However, because increased intra-ER calcium concentration can lead to increased apoptosis following ER stress (37), it remains possible that mutations in presenilin sensitize neurons to mild but repeated ER stress imposed from the external environment by conditions such as hypoxia or nutrient starvation (120). Given the progressive and lengthy course of $\mathrm{AD}$, multiple chronic insults that independently elicit ER stress could cumulatively synergize with mutant presenilin to damage neurons.

\section{Cancer and Chemotherapy}

Hypoxia is thought to disrupt the normally oxidative environment within the ER, thereby leading to protein misfolding. Hypoxia is a potent trigger of PERK signaling in cultured mammalian cell lines $(121,122)$. As discussed above, PERK activity leads to phosphorylation of the translation initiation factor eIF2 $a$ and suppression of protein synthesis from the vast majority of mRNAs in the cell. Cells bearing genetic mutations that disrupt the function of PERK or its downstream effectors eIF2 $a$ and ATF-4 all show impaired survival and proliferation when challenged with low oxygen levels $(121,122)$. These studies provide genetic evidence that PERK signaling can promote cell survival during hypoxia.

Hypoxia develops frequently in solid tumors, as rapid cancer cell proliferation outpaces the ability of the vasculature to deliver oxygen. The presence of hypoxia in cancer has significant clinical implications, including resistance to chemo- and radiotherapy, increased likelihood for metastases, and worse prognoses (123). Several studies have linked PERK signaling with enhanced tumor growth and survival under hypoxic conditions. Biet al. (122) provided molecular evidence of PERK activation in a wide variety of primary human 
tumors, including melanomas, glioblastom as, and breast and cervical cancers. In the same study, they experimentally demonstrated that malignant murine cells with genetically compromised PERK or eIF2a function formed smaller tumors and were more prone to apoptosis. In another mouse model of tumor growth, Blais et al. (124) saw impaired vasculogenesis and cancer cell proliferation when PERK signaling was ablated. Intriguingly, these authors also identified uORFs in several angiogenesis-promoting genes and suggested that their translation was stimulated by PERK signaling in a fashion analogous to enhanced protein synthesis from the mRNA. These studies suggest a model by which tumor cells manipulate PERK signaling to (a) enhance viability in a hypoxic setting by reducing translational activity, thereby reducing metabolic demands within the cell, and $(b)$ promote tumor growth by increasing the production of angiogenic factors in response to low oxygen levels.

Less is known about the role of PERK's proapoptotic functions, if any, in tumorigenesis. The attenuation of translation imposed by PERK, while providing protective benefits in moderation, would ultimately be detrimental if protein synthesis fell below levels necessary to sustain cellular functions. It is unclear if tumor cells are especially tolerant of PERKimposed translational attenuation. PERK signaling also directly promotes cell death through specific transcriptional induction and activation of the CHOP gene (24). Within solid tumors, increased CHOP levels have been reported, indicating that PERK signaling may be promoting apoptosis in these regions $(125,126)$, although it should be borne in mind that CHOP may also have an-tiapoptotic functions under certain circumstances $(127,128)$. It is unclear how tumor cells balance the beneficial versus cytotoxic outputs derived from PERK signaling. Areas of central necrosis are often observed within rapidly growing solid tumors and could be gross manifestations of dynamic switching between the protective and toxic properties of PERK signaling triggered after hypoxia. Selective modulation of PERK signaling could provide therapeutic opportunities for inhibiting tumor progression when used in combination with agents that control vascular outgrowth and oxygen supply.

Enhanced survival of tumor cells under hypoxic conditions mediated by PERK is not the only mechanism by which the UPR may be involved in carcinogenesis. Other components of the UPR, including XBP-1 and the ER chaperone GRP78, have also been shown to be upregulated in many cancers (Figure 4) and implicated in tumor growth $(129,130)$. Furthermore, ER stress has been shown to increase the degradation of the tumor suppressor p53 (131). Thus, there may be multiple different mechanisms by which ER stress may favor malignant transformation, and manipulation of the UPR may prove to be a new modality for treating cancer.

Multiple myeloma (MM) is a hematologic malignancy that arises from the transformation of immunoglobulin-secreting plasma cells. A hallmark feature of both normal and transformed plasma cells is the extensive expansion of the ER to accommodate immunoglobulin synthesis (Figure 5). The IRE1 branch of the UPR is required for plasma cell generation, and genetic ablation of Irela or its downstream effector, $X b p-1$, severely compromises the development of plasma cells from precursor B-lymphocytes $(132,133)$. IRE1 signaling via XBP-1 production functions in plasma and MM cells by optimizing the protein-folding capacity of the ER for immunoglobulin production and secretion (5), but it is likely that XBP-1 also plays additional roles in the development and proliferation of plasma cells, as overexpression of XBP-1 in plasma cells and their precursor lymphocytes causes the development of an MM-like disease in transgenic mice (133a). Intriguingly, while IRE1 signaling is activated in plasma cells for normal development and function, the parallel PERK branch of the UPR appears to be dispensable and/or inactive in these cells (133). The selective activation of IRE1 in the absence of PERK raises the question of the identity of the physiologic stimulus that triggers IRE1 signaling in plasma cells because, at least in cell 
culture studies, agents that elicit ER stress activate both IRE1 and PERK branch signaling. Plasma cells may employ cell-type-specific mechanisms, such as the transcription factor Blimp-1 (5), to specifically use distinct UPR signaling pathways during their development.

Besides their role in the development of plasma and MM cells, UPR signaling pathways may also function in the therapeutic treatment of MM. Proteasome inhibitors (PIs) such as bortezomib (Velcade) have shown clinical efficacy in the treatment of MM (134). Bortezomib selectively inhibits the $26 \mathrm{~S}$ subunit of the proteasome, a multi-protein complex that degrades ubiquitinated proteins, including terminally misfolded ER proteins, in eukaryotic cells (135). The molecular mechanism by which proteasomal inhibition kills MM cells is poorly understood. However, emerging reports link the cytotoxicity of PIs to the modulation of UPR signaling pathways. PIs compromised IRE1 signaling in MM cells (136). This finding was quite surprising because proteasome inhibition leads to misfolded protein accumulation, which, as discussed above, is a classic source of ER stress that activates IRE1. Although IRE1 signaling appeared to be inhibited by PIs, another study of human MM cell lines indicated that the PERK branch was activated after PI exposure, as evidenced by PERK and eIF2 $a$ phosphorylation, and by ATF-4 and CHOP protein synthesis (137). This study proposed a mechanism of PI action in which proteasome inhibition caused the accumulation of misfolded proteins in the ER, selective activation of PERK, and cytotoxicity mediated by downstream PERK signaling components. In contrast, another group detected phosphorylation of eIF2 $a$ and ATF-4 and CHOP protein synthesis after PI treatment in mouse fibroblasts, but did not observe PERK activation (138). Instead, this group saw phosphorylation and activation ofGCN2, a kinase related to PERK, whose activity is triggered by amino acid deprivation instead of ER stress but shares the same downstream eIF2a-mediated signaling outputs as PERK. In this study, they proposed a mechanism of PI efficacy in which proteasome inhibition impairs the production of free amino acids from recycled proteins, thereby triggering activation of GCN2 instead of PERK. It is unclear if these differences between the two studies arise from cell-type-specific differences in the sensitivity of GCN2 and PERK activation to PIs, although in both cases eIF2a phosphorylation by either PERK or GCN2 would result in translational attenuation and ATF-4/CHOP protein synthesis. Note that a combination of bortezomib and ER stressors showed synergistic action in killing pancreatic carcinoma cells (139), consistent with the hypothesis that the two agents acted in the same pathway.

UPR signaling pathways have been reported to modulate the efficacies of various chemotherapeutic agents (Table 1). For example, UPR activation dampens the therapeutic efficacy of topoisomerase inhibitors, such as etoposide $(140,141)$, which exert their cytotoxic effects by interfering with the replication of DNA in tumor cells. UPR activity reduces topoisomerase levels through an unclear mechanism (140). Therefore, removing the target for etoposide action would account for increased resistance to topoisomerase-type agents in tumor cells subjected to ER stress.

UPR activation, in contrast, enhances the efficacy of cisplatin (137). Cisplatin is thought to exert its cytotoxic effects by widespread chemical cross-linking of nucleic acids and proteins in the cells. Cisplatin has been reported to elicit protein misfolding in treated cells and may directly cause ER stress by overloading the protein-folding capacity of the ER (137). The combination of cisplatin and other protein-misfolding agents could trigger cell death by eliciting cytotoxic outputs from UPR signaling pathways.

It has also been proposed that agents that cause ER stress can be used directly as chemotherapeutic agents. The fungal metabolite brefeldin A induces ER stress by blocking ER to Golgi trafficking and has been shown to kill chronic lymphocytic leukemia cells (142), presumably by causing ER stress, although other mechanisms cannot be ruled out. 
The Newcastle disease virus is a pathogen for birds, but is essentially nonpathogenic for humans. It has been shown to be oncolytic for human malignant cells, probably by causing ER stress (143). The basis for the apparently selective effect of ER stressors on neoplastic cells is not yet known, but it may be related to the high basal level of ER stress in these cells, which would render them incapable of dealing with additional stress imposed by chemicals or viruses.

\section{Conclusion}

The mammalian cell has evolved a complex and intertwined set of signaling pathways to respond to ER stresses, both physiological and pathological. Much remains unknown about these pathways, but it is becoming clear that ER stress and the UPR are intimately involved in many different diseases and may well play critical pathogenic roles. Understanding the molecular basis of the UPR will be important in both confirming the importance of ER stress for many diseases and designing new therapeutic modalities to treat these diseases by modulating the UPR. Note that in some disease states (e.g., pancreatic $\beta$ cells in DM), it may be beneficial to relieve ER stress and/or block certain outputs from the UPR, whereas in other diseases (e.g., viral infections), inducing ER stress and/or increasing the UPR may be needed for a therapeutic effect. However, as each pathway in the UPR can lead to either cell survival or death, any new therapeutic agent must be carefully tested in suitable model organisms, to insure that unexpected side effects or even results diametrically opposite to those desired do not ensue.

\section{Acknowledgments}

We thank Scott Oakes, Brad Stohr, and Matt LaVail for helpful discussions and suggestions. J.L. and P.W. acknowledge support from the Amyotrophic Lateral Sclerosis Association, United States Department of Defense, John Douglas French Alzheimer's Foundation, and National Institutes of Health. P.W. is an Investigator of the Howard Hughes Medical Institute. T.S.B.Y. acknowledges support from the National Institutes of Health and Department of Veterans Affairs. Figures 3 and 4 were obtained at the San Francisco Veterans Affairs Medical Center and Liver Center Microscopy and Advanced Imaging Core, with the assistance of Sandra Huling and Ivy Hsieh.

\section{Literature Cited}

1. Bernales S, Papa FR, Walter P. Intracellular signaling by the unfolded protein response. Annu Rev Cell Dev Biol. 2006; 22:487-508. [PubMed: 16822172]

2. Calfon M, Zeng H, Urano F, Till JH, Hubbard SR, et al. IRE1 couples endoplasmic reticulum load to secretory capacity by processing the XBP-1 mRNA. Nature. 2002; 415:92-96. [PubMed: 11780124]

3. Yoshida H, Matsui T, Yamamoto A, Okada T, Mori K. XBP1 mRNA is induced by ATF6 and spliced by IRE1 in response to ER stress to produce a highly active transcription factor. Cell. 2001; 107:881-91. [PubMed: 11779464] 3a Sidrauski C, Walter P. The transmembrane kinase Ire1p is a site-specific endonuclease that initiates mRNA splicing in the unfolded protein response. Cell. 1997; 90:1031-39. [PubMed: 9323131]

4. Lee AH, Iwakoshi NN, Glimcher LH. XBP-1 regulates a subset of endoplasmic reticulum resident chaperone genes in the unfolded protein response. Mol Cell Biol. 2003; 23:7448-59. [PubMed: 14559994]

5. Shaffer AL, Shapiro-Shelef M, Iwakoshi NN, Lee AH, Qian SB, et al. XBP1, downstream of Blimp-1, expands the secretory apparatus and other organelles, and increases protein synthesis in plasma cell differentiation. Immunity. 2004; 21:81-93. [PubMed: 15345222]

6. Urano F, Wang X, Bertolotti A, Zhang Y, Chung P, et al. Coupling of stress in the ER to activation of JNK protein kinases by transmembrane protein kinase IRE1. Science. 2000; 287:664-66. [PubMed: 10650002] 
7. Nishitoh H, Matsuzawa A, Tobiume K, Saegusa K, Takeda K, et al. ASK1 is essential for endoplasmic reticulum stress-induced neuronal cell death triggered by expanded polyglutamine repeats. Genes Dev. 2002; 16:1345-55. [PubMed: 12050113]

8. Barr RK, Bogoyevitch MA. The c-Jun N-terminal protein kinase family of mitogen-activated protein kinases (JNK MAPKs). Int J Biochem Cell Biol. 2001; 33:1047-63. [PubMed: 11551821]

9. Takeda K, Matsuzawa A, Nishitoh H, Ichijo H. Roles of MAPKKK ASK1 in stress-induced cell death. Cell Struct Funct. 2003; 28:23-29. [PubMed: 12655147]

10. Yoneda T, Imaizumi K, Oono K, Yui D, Gomi F, et al. Activation of caspase-12, an endoplastic reticulum (ER) resident caspase, through tumor necrosis factor receptor-associated factor 2dependent mechanism in response to the ER stress. J Biol Chem. 2001; 276:13935-40. [PubMed: 11278723]

11. Nakagawa T, Zhu H, Morishima N, Li E, Xu J, et al. Caspase-12 mediates endoplasmic-reticulumspecific apoptosis and cytotoxicity by amyloid- $\beta$. Nature. 2000; 403:98-103. [PubMed: 10638761]

12. Saleh M, Mathison JC, Wolinski MK, Bensinger SJ, Fitzgerald P, et al. Enhanced bacterial clearance and sepsis resistance in caspase-12-deficient mice. Nature. 2006; 440:1064-68. [PubMed: 16625199]

13. Xue Y, Daly A, Yngvadottir B, Liu M, Coop G, et al. Spread of an inactive form of caspase-12 in humans is due to recent positive selection. Am J Hum Genet. 2006; 78:659-70. [PubMed: 16532395]

14. Hitomi J, Katayama T, Eguchi Y, Kudo T, Taniguchi M, et al. Involvement of caspase-4 in endoplasmic reticulum stress-induced apoptosis and A $\beta$-induced cell death. J Cell Biol. 2004; 165:347-56. [PubMed: 15123740]

15. Tirasophon W, Lee K, Callaghan B, Welihinda A, Kaufman RJ. The endoribonuclease activity of mammalian IRE1 autoregulates its mRNA and is required for the unfolded protein response. Genes Dev. 2000; 14:2725-36. [PubMed: 11069889]

16. Hollien J, Weissman JS. Decay of endoplasmic reticulum-localized mRNAs during the unfolded protein response. Science. 2006; 313:104-7. [PubMed: 16825573]

17. Harding HP, Zhang Y, Ron D. Protein translation and folding are coupled by an endoplasmicreticulum-resident kinase. Nature. 1999; 397:271-74. [PubMed: 9930704]

18. Anderson P, Kedersha N. Visibly stressed: the role of eIF2, TIA-1, and stress granules in protein translation. Cell Stress Chaperones. 2002; 7:213-21. [PubMed: 12380690]

19. Jiang HY, Jiang L, Wek RC. The eukaryotic initiation factor-2 kinase pathway facilitates differential GADD45 a expression in response to environmental stress. J Biol Chem. 2007; 282:3755-65. [PubMed: 17170114]

20. Wek RC, Jiang HY, Anthony TG. Coping with stress: eIF2 kinases and translational control. Biochem Soc Trans. 2006; 34:7-11. [PubMed: 16246168]

21. Harding HP, Novoa I, Zhang Y, Zeng H, Wek R, et al. Regulated translation initiation controls stress-induced gene expression in mammalian cells. Mol Cell. 2000; 6:1099-108. [PubMed: 11106749]

22. Novoa I, Zeng H, Harding HP, Ron D. Feedback inhibition of the unfolded protein response by GADD34-mediated dephosphorylation of eIF2a. J Cell Biol. 2001:1011-22. [PubMed: 11381086]

23. Harding HP, Zhang Y, Bertolotti A, Zeng H, Ron D. Perk is essential for trans-lational regulation and cell survival during the unfolded protein response. Mol Cell. 2000; 5:897-904. [PubMed: 10882126]

24. Zinszner H, Kuroda M, Wang X, Batchvarova N, Lightfoot RT, et al. CHOP is implicated in programmed cell death in response to impaired function of the endoplasmic reticulum. Genes Dev. 1998; 12:982-95. [PubMed: 9531536]

25. Marciniak SJ, Yun CY, Oyadomari S, Novoa I, Zhang Y, et al. CHOP induces death by promoting protein synthesis and oxidation in the stressed endoplasmic reticulum. Genes Dev. 2004; 18:306677. [PubMed: 15601821]

26. Ohoka N, Yoshii S, Hattori T, Onozaki K, Hayashi H. TRB3, a novel ER stress-inducible gene, isinduced via ATF4-CHOP pathway and is involved in cell death. EMBO J. 2005; 24:1243-55. [PubMed: 15775988] 
27. Zhang K, Shen X, Wu J, Sakaki K, Saunders T, et al. Endoplasmic reticulum stress activates cleavage of CREBH to induce a systemic inflammatory response. Cell. 2006; 124:587-99. [PubMed: 16469704]

28. Kondo S, Murakami T, Tatsumi K, Ogata M, Kanemoto S, et al. OASIS, a CREB/ATF-family member, modulates UPR signalling in astrocytes. Nat Cell Biol. 2005; 7:186-94. [PubMed: 15665855]

29. Kondo S, Saito A, Hino S, Murakami T, Ogata M, et al. BBF2H7, a novel trans-membrane bZIP transcription factor, is a new type of endoplasmic reticulum stress transducer. Mol Cell Biol. 2007; 27:1716-29. [PubMed: 17178827]

30. Stirling J, O'Hare P. CREB4, a transmembrane bZip transcription factor and potential new substrate for regulation and cleavage by S1P. Mol Biol Cell. 2006; 17:413-26. [PubMed: 16236796]

31. DenBoer LM, Hardy-Smith PW, Hogan MR, Cockram GP, Audas TE, et al. Luman is capable of binding and activating transcription from the unfolded protein response element. Biochem Biophys Res Commun. 2005; 331:113-19. [PubMed: 15845366]

32. Haze K, Yoshida H, Yanagi H, Yura T, Mori K. Mammalian transcription factor ATF6 is synthesized as a transmembrane protein and activated by proteolysis in response to endoplasmic reticulum stress. Mol Biol Cell. 1999; 10:3787-99. [PubMed: 10564271]

33. Ye J, Rawson RB, Komuro R, Chen X, Dave UP, et al. ERstress induces cleavage of membranebound ATF6 by the same proteases that process SREBPs. Mol Cell. 2000; 6:1355-64. [PubMed: 11163209]

34. Yoshida H, Okada T, Haze K, Yanagi H, Yura T, et al. ATF6 activated by proteol-ysis binds in the presence of NF-Y (CBF) directly to the cis-acting element responsible for the mammalian unfolded protein response. Mol Cell Biol. 2000; 20:6755-67. [PubMed: 10958673]

35. Nakanishi K, Sudo T, Morishima N. Endoplasmic reticulum stress signaling transmitted by ATF6 mediates apoptosis during muscle development. J Cell Biol. 2005; 169:555-60. [PubMed: 15897261]

36. Gotoh T, Oyadomari S, Mori K, Mori M. Nitric oxide-induced apoptosis in RAW 264.7 macrophages is mediated by endoplasmic reticulum stress pathway involving ATF6 and CHOP. J Biol Chem. 2002; 277:12343-50. [PubMed: 11805088]

37. Oakes SA, Lin SS, Bassik MC. The control of endoplasmic reticulum-initiated apoptosis by the BCL-2 family of proteins. Curr Mol Med. 2006; 6:99-109. [PubMed: 16472117]

38. Wei MC, Zong WX, Cheng EH, Lindsten T, Panoutsakopoulou V, et al. Proapoptotic BAX and BAK: a requisite gateway to mitochondrial dysfunction and death. Science. 2001; 292:727-30. [PubMed: 11326099]

39. Nutt LK, Pataer A, Pahler J, Fang B, Roth J, et al. Bax and Bak promote apoptosis by modulating endoplasmic reticular and mitochondrial $\mathrm{Ca}^{2+}$ stores. J Biol Chem. 2002; 277:9219-25. [PubMed: 11741880]

40. Zong WX, Li C, Hatzivassiliou G, Lindsten T, Yu QC, et al. Bax and Bak can localize to the endoplasmic reticulum to initiate apoptosis. J Cell Biol. 2003; 162:59-69. [PubMed: 12847083]

41. Oakes SA, Scorrano L, Opferman JT, Bassik MC, Nishino M, et al. Proapoptotic BAX and BAK regulate the type 1 inositol trisphosphate receptor and calcium leak from the endoplasmic reticulum. Proc Natl Acad Sci USA. 2005; 102:105-10. [PubMed: 15613488]

42. Hetz C, Bernasconi P, Fisher J, Lee AH, Bassik MC, et al. Proapoptotic BAX and BAK modulate the unfolded protein response by a direct interaction with IRE1a. Science. 2006; 312:572-76. [PubMed: 16645094]

43. Rutkowski DT, Arnold SM, Miller CN, Wu J, Li J, et al. Adaptation to ER stress is mediated by differential stabilities of prosurvival and proapoptotic mRNAs and proteins. PLoS Biol. 2006; 4:e374. [PubMed: 17090218] 43a Lin JH, Li H, Yasumura D, Cohen HR, Zhang C, et al. IRE1 signaling affects cell fate during the unfolded protein response. Science. $2007 \mathrm{In}$ press.

44. Delepine M, Nicolino M, Barrett T, Golamaully M, Lathrop GM, Julier C. EIF2AK3, encoding translation initiation factor 2- $\beta$ kinase 3 , is mutated in patients with Wolcott-Rallison syndrome. Nat Genet. 2000; 25:406-9. [PubMed: 10932183] 
45. Harding HP, Zeng H, Zhang Y, Jungries R, Chung P, et al. Diabetes mellitus and exocrine pancreatic dysfunction in perk ${ }^{-/-}$mice reveals a role for translational control in secretory cell survival. Mol Cell. 2001; 7:1153-63. [PubMed: 11430819]

46. Scheuner D, Song B, McEwen E, Liu C, Laybutt R, et al. Translational control is required for the unfolded protein response and in vivo glucose homeostasis. Mol Cell. 2001; 7:1165-76. [PubMed: 11430820]

47. Zhang W, Feng D, Li Y, Iida K, McGrath B, et al. PERK EIF2AK3 control of pancreatic $\beta$ cell differentiation and proliferation is required for postnatal glucose homeostasis. Cell Metab. 2006; 4:491-97. [PubMed: 17141632]

48. Lee AH, Chu GC, Iwakoshi NN, Glimcher LH. XBP-1 is required for biogenesis of cellular secretory machinery of exocrine glands. EMBO J. 2005; 24:4368-80. [PubMed: 16362047]

49. Inoue H, Tanizawa Y, Wasson J, Behn P, Kalidas K, et al. A gene encoding a transmembrane protein is mutated in patients with diabetes mellitus and optic atrophy (Wolfram syndrome). Nat Genet. 1998; 20:143-48. [PubMed: 9771706]

50. Strom TM, Hortnagel K, Hofmann S, Gekeler F, Scharfe C, et al. Diabetes in-sipidus, diabetes mellitus, optic atrophy and deafness (DIDMOAD) caused by mutations in a novel gene (wolframin) coding for a predicted transmembrane protein. Hum Mol Genet. 1998; 7:2021-28. [PubMed: 9817917]

51. Fonseca SG, Fukuma M, Lipson KL, Nguyen LX, Allen JR, et al. WFS1 is a novel component of the unfolded protein response and maintains homeostasis of the endoplasmic reticulum in pancreatic $\beta$-cells. J Biol Chem. 2005; 280:39609-15. [PubMed: 16195229]

52. Ueda K, Kawano J, Takeda K, Yujiri T, Tanabe K, et al. Endoplasmic reticulum stress induces $W f_{s} 1$ gene expression in pancreatic $\beta$-cells via transcriptional activation. Eur J Endocrinol. 2005; 153:167-76. [PubMed: 15994758]

53. Ishihara H, Takeda S, Tamura A, Takahashi R, Yamaguchi S, et al. Disruption of the WFS1 gene in mice causes progressive $\beta$-cell loss and impaired stimulus-secretion coupling in insulin secretion. Hum Mol Genet. 2004; 13:1159-70. [PubMed: 15056606]

54. Riggs AC, Bernal-Mizrachi E, Ohsugi M, Wasson J, Fatrai S, et al. Mice conditionally lacking the Wolfram gene in pancreatic islet $\beta$ cells exhibit diabetes as a result of enhanced endoplasmic reticulum stress and apoptosis. Diabetologia. 2005; 48:2313-21. [PubMed: 16215705]

55. Wang J, Takeuchi T, Tanaka S, Kubo SK, Kayo T, et al. A mutation in the insulin 2 gene induces diabetes with severe pancreatic $\beta$-cell dysfunction in the Mody mouse. J Clin Invest. 1999; 103:27-37. [PubMed: 9884331]

56. Leroux L, Desbois P, Lamotte L, Duvillie B, Cordonnier N, et al. Compensatory responses in mice carrying a null mutation for Ins1 or Ins2. Diabetes. 2001; 50:S150-53. [PubMed: 11272179]

57. Oyadomari S, Koizumi A, Takeda K, Gotoh T, Akira S, et al. Targeted disruption of the Chop gene delays endoplasmic reticulum stress-mediated diabetes. J Clin Invest. 2002; 109:525-32. [PubMed: 11854325]

58. Cardozo AK, Ortis F, Storling J, Feng YM, Rasschaert J, et al. Cytokines down-regulate the sarcoendoplasmic reticulum pump $\mathrm{Ca}^{2+}$ ATPase $2 \mathrm{~b}$ and deplete endoplasmic reticulum $\mathrm{Ca}^{2+}$, leading to induction of endoplasmic reticulum stress in pancreatic $\beta$-cells. Diabetes. 2005; 54:45261. [PubMed: 15677503]

59. Oyadomari S, Takeda K, Takiguchi M, Gotoh T, Matsumoto M, et al. Nitric oxide-induced apoptosis in pancreatic $\beta$ cells is mediated by the endoplasmic reticulum stress pathway. Proc Natl Acad Sci USA. 2001; 98:10845-50. [PubMed: 11526215]

60. Laybutt DR, Preston AM, Akerfeldt MC, Kench JG, Busch AK, et al. Endoplasmic reticulum stress contributes to $\beta$ cell apoptosis in type 2 diabetes. Diabetologia. 2007; 1:1.

61. Lipson KL, Fonseca SG, Ishigaki S, Nguyen LX, Foss E, et al. Regulation of insulin biosynthesis in pancreatic $\beta$ cells by an endoplasmic reticulum-resident protein kinase IRE1. Cell Metab. 2006; 4:245-54. [PubMed: 16950141]

62. Cnop M, Ladriere L, Hekerman P, Ortis F, Cardozo AK, et al. Selective inhibition of eukaryotic translation initiation factor $2 a$ dephosphorylation potentiates fatty acid-induced endoplasmic reticulum stress and causes pancreatic $\beta$-cell dysfunction and apoptosis. J Biol Chem. 2007; 282:3989-97. [PubMed: 17158450] 
63. Scheuner D, Vander Mierde D, Song B, Flamez D, Creemers JW, et al. Control of mRNA translation preserves endoplasmic reticulum function in $\beta$ cells and maintains glucose homeostasis. Nat Med. 2005; 11:757-64. [PubMed: 15980866]

64. özcan U, Cao Q, Yilmaz E, Lee AH, Iwakoshi NN, et al. Endoplasmic reticulum stress links obesity, insulin action, and type 2 diabetes. Science. 2004; 306:457-61. [PubMed: 15486293]

65. Du K, Herzig S, Kulkarni RN, Montminy M. TRB3: a tribbles homolog that inhibits Akt/PKB activation by insulin in liver. Science. 2003; 300:1574-77. [PubMed: 12791994]

66. Özcan U, Yilmaz E, Özcan L, Furuhashi M, Vaillancourt E, et al. Chemical chaperones reduce ER stress and restore glucose homeostasis in a mouse model of type 2 diabetes. Science. 2006; 313:1137-40. [PubMed: 16931765]

67. Nakatani Y, Kaneto H, Kawamori D, Yoshiuchi K, Hatazaki M, et al. Involvement of endoplasmic reticulum stress in insulin resistance and diabetes. J Biol Chem. 2005; 280:847-51. [PubMed: 15509553] 67a Thameem F, Farook VS, Bogardus C, Prochazka M. Association of amino acid variants in the activating transcription factor 6 gene (ATF6) on 1q21-q23 with type 2 diabetes in Pima Indians. Diabetes. 2006; 55:839-42. [PubMed: 16505252] 67b Meex SJR, van Greevenbroek MMJ, Ayoubi TA, Vlietinck R, van Vliet-Ostaptchouk JV, et al. Activating transcription factor 6 polymorphisms and haplotypes are associated with impaired glucose homeostasis and type 2 diabetes in Dutch Caucasians. J Clin Endocrinol Metabol. 2007; 92:2720-25.

68. Kharroubi I, Ladriere L, Cardozo AK, Dogusan Z, Cnop M, Eizirik DL. Free fatty acids and cytokines induce pancreatic $\beta$-cell apoptosis by different mechanisms: role of nuclear factor-B and endoplasmic reticulum stress. Endocrinology. 2004; 145:5087-96. [PubMed: 15297438]

69. Harding HP, Zhang Y, Zeng H, Novoa I, Lu PD, et al. An integrated stress response regulates amino acid metabolism and resistance to oxidative stress. Mol Cell. 2003; 11:619-33. [PubMed: 12667446]

70. Yusta B, Baggio LL, Estall JL, Koehler JA, Holland DP, et al. GLP-1 receptor activation improves $\beta$ cell function and survival following induction of endoplasmic reticulum stress. Cell Metab. 2006; 4:391-406. [PubMed: 17084712]

71. Lu PD, Jousse C, Marciniak SJ, Zhang Y, Novoa I, et al. Cytoprotection by pre-emptive conditional phosphorylation of translation initiation factor 2. EMBO J. 2004; 23:169-79. [PubMed: 14713949]

72. Baltzis D, Qu LK, Papadopoulou S, Blais JD, Bell JC, et al. Resistance to vesicular stomatitis virus infection requires a functional cross talk between the eukaryotic translation initiation factor 2kinases PERK and PKR. J Virol. 2004; 78:12747-61. [PubMed: 15542627]

73. Perkins DJ, Barber GN. Defects in translational regulation mediated by the- sub-unit of eukaryotic initiation factor 2 inhibit antiviral activity and facilitate the malignant transformation of human fibroblasts. Mol Cell Biol. 2004; 24:2025-40. [PubMed: 14966282]

74. Chou J, Roizman B. Herpes simplex virus $1 \gamma(1) 34.5$ gene function, which blocks the host response to infection, maps in the homologous domain of the genes expressed during growth arrest and DNA damage. Proc Natl Acad Sci USA. 1994; 91:5247-51. [PubMed: 8202476]

75. Whitley RJ, Kern ER, Chatterjee S, Chou J, Roizman B. Replication, establishment of latency, and induced reactivation of herpes simplex virus $\gamma 134.5$ deletion mutants in rodent models. J Clin Invest. 1993; 91:2837-43. [PubMed: 8390490]

76. Boyce M, Bryant KF, Jousse C, Long K, Harding HP, et al. A selective inhibitor of eIF2a dephosphorylation protects cells from ER stress. Science. 2005; 307:935-39. [PubMed: 15705855]

77. Netherton CL, Parsley JC, Wileman T. African swine fever virus inhibits induction of the stressinduced proapoptotic transcription factor CHOP/GADD153. J Virol. 2004; 78:10825-28. [PubMed: 15367650]

78. Rivera J, Abrams C, Hernaez B, Alcazar A, Escribano JM, et al. The MyD116 African swine fever virus homologue interacts with the catalytic subunit of protein phosphatase 1 and activates its phosphatase activity. J Virol. 2007; 81:2923-29. [PubMed: 17215279]

79. Pavio N, Romano PR, Graczyk TM, Feinstone SM, Taylor DR. Protein synthesis and endoplasmic reticulum stress can be modulated by the hepatitis $\mathrm{C}$ virus envelope protein $\mathrm{E} 2$ through the eukaryotic initiation factor 2akinase PERK. J Virol. 2003; 77:3578-85. [PubMed: 12610133] 
80. Mulvey M, Arias C, Mohr I. Maintenance of ER homeostasis in HSV-1 infected cells through the association of a viral glycoprotein with PERK, a cellular ER-stress sensor. J Virol. 2007; 17:17.

81. Liberman E, Fong YL, Selby MJ, Choo QL, Cousens L, et al. Activation of the grp78 and grp94 promoters by hepatitis C virus E2 envelope protein. J Virol. 1999; 73:3718-22. [PubMed: 10196264]

82. Isler JA, Skalet AH, Alwine JC. Human cytomegalovirus infection activates and regulates the unfolded protein response. J Virol. 2005; 79:6890-99. [PubMed: 15890928]

83. Tardif KD, Mori K, Kaufman RJ, Siddiqui A. Hepatitis C virus suppresses the IRE1-XBP1 pathway of the unfolded protein response. J Biol Chem. 2004; 279:17158-64. [PubMed: 14960590]

84. Yoshida H, Matsui T, Hosokawa N, Kaufman RJ, Nagata K, et al. A time-dependent phase shift in the mammalian unfolded protein response. Dev Cell. 2003; 4:265-71. [PubMed: 12586069]

85. Tirosh B, Iwakoshi NN, Lilley BN, Lee AH, Glimcher LH, et al. Human cytomegalovirus protein US11 provokes an unfolded protein response that may facilitate the degradation of class I major histocompatibility complex products. J Virol. 2005; 79:2768-79. [PubMed: 15708995]

86. Smith JA, Schmechel SC, Raghavan A, Abelson M, Reilly C, et al. Reovirus induces and benefits from an integrated cellular stress response. J Virol. 2006; 80:2019-33. [PubMed: 16439558]

87. Huang ZM, Tan T, Yoshida H, Mori K, Ma Y, et al. Activation of hepatitis B virus S promoter by a cell type-restricted IRE1-dependent pathway induced by endoplasmic reticulum stress. Mol Cell Biol. 2005; 25:7522-33. [PubMed: 16107700]

88. Liu N, Scofield VL, Qiang W, Yan M, Kuang X, et al. Interaction between en-doplasmic reticulum stress and caspase 8 activation in retrovirus MoMuLV-ts1-infected astrocytes. Virology. 2006; 348:398-405. [PubMed: 16466764]

89. Dimcheff DE, Askovic S, Baker AH, Johnson-Fowler C, Portis JL. Endoplasmic reticulum stress is a determinant of retrovirus-induced spongiform neurodegeneration. J Virol. 2003; 77:12617-29. [PubMed: 14610184]

90. Dimcheff DE, Faasse MA, McAtee FJ, Portis JL. Endoplasmic reticulum (ER) stress induced by a neurovirulent mouse retrovirus is associated with prolonged BiP binding and retention of a viral protein in the ER. J Biol Chem. 2004; 279:33782-90. [PubMed: 15178688]

91. Williams BL, Lipkin WI. Endoplasmic reticulum stress and neurodegeneration in rats neonatally infected with borna disease virus. J Virol. 2006; 80:8613-26. [PubMed: 16912310]

92. Jordan R, Wang L, Graczyk TM, Block TM, Romano PR. Replication of a cytopathic strain of bovine viral diarrhea virus activates PERK and induces endoplasmic reticulum stress-mediated apoptosis of MDBK cells. J Virol. 2002; 76:9588-99. [PubMed: 12208938]

93. Su HL, Liao CL, Lin YL. Japanese encephalitis virus infection initiates endoplasmic reticulum stress and an unfolded protein response. J Virol. 2002; 76:4162-71. [PubMed: 11932381]

94. Davies SE, Portmann BC, O'Grady JG, Aldis PM, Chaggar K, et al. Hepatic histological findings after transplantation for chronic hepatitis $\mathrm{B}$ virus infection, including a unique pattern of fibrosing cholestatic hepatitis. Hepatology. 1991; 13:150-57. [PubMed: 1988336]

95. Meuleman P, Libbrecht L, Wieland S, DeVos R, Habib N, et al. Immune suppression uncovers endogenous cytopathic effects of the hepatitis B virus. J Virol. 2006; 80:2797-807. [PubMed: 16501088]

96. Lau JY, Bain VG, Davies SE, O'Grady JG, Alberti A, et al. High-level expression of hepatitis B viral antigens in fibrosing cholestatic hepatitis. Gastroenterology. 1992; 102:956-62. [PubMed: 1537531]

97. Foo NC, Ahn BY, Ma X, Hyun W, Yen TS. Cellular vacuolization and apoptosis induced by hepatitis B virus large surface protein. Hepatology. 2002; 36:1400-7. [PubMed: 12447865]

98. Xu Z, Jensen G, Yen TS. Activation of hepatitis B virus S promoter by the viral large surface protein via induction of stress in the endoplasmic reticulum. J Virol. 1997; 71:7387-92. [PubMed: 9311817]

99. Berson EL. Retinitis pigmentosa. The Friedenwald Lecture Invest. Ophthalmol Vis Sci. 1993; 34:1659-76. 
100. Sohocki MM, Daiger SP, Bowne SJ, Rodriquez JA, Northrup H, et al. Prevalence of mutations causing retinitis pigmentosa and other inherited retinopathies. Hum Mutat. 2001; 17:42-51. [PubMed: 11139241]

101. Liu X, Garriga P, Khorana HG. Structure and function in rhodopsin: correct folding and misfolding in two point mutants in the intradiscal domain of rhodopsin identified in retinitis pigmentosa. Proc Natl Acad Sci USA. 1996; 93:4554-59. [PubMed: 8643442]

102. Kaushal S, Khorana HG. Structure and function in rhodopsin 7 Point mutations associated with autosomal dominant retinitis pigmentosa. Biochemistry. 1994; 33:6121-28. [PubMed: 8193125]

103. Sung CH, Schneider BG, Agarwal N, Papermaster DS, Nathans J. Functional heterogeneity of mutant rhodopsins responsible for autosomal dominant retinitis pigmentosa. Proc Natl Acad Sci USA. 1991; 88:8840-44. [PubMed: 1924344]

104. Ryoo HD, Domingos PM, Kang MJ, Steller H. Unfolded protein response in a Drosophila model for retinal degeneration. EMBO J. 2007; 26:242-52. [PubMed: 17170705]

105. Natl. Inst. Aging Reagan Inst. Work. Group Diagn. Criteria Neuropathol. Assess. Alzheimer's Dis. Consensus recommendations for the postmortem diagnosis of Alzheimer's disease. Neurobiol Aging. 1997; 18:S1-2. [PubMed: 9330978]

106. Unterberger U, Hoftberger R, Gelpi E, Flicker H, Budka H, et al. Endoplasmic reticulum stress features are prominent in Alzheimer disease but not in prion diseases in vivo. J Neuropathol Exp Neurol. 2006; 65:348-57. [PubMed: 16691116]

107. Hoozemans JJ, Veerhuis R, Van Haastert ES, Rozemuller JM, Baas F, et al. The unfolded protein response is activated in Alzheimer's disease. Acta Neuropathol. 2005; 110:165-72. [PubMed: 15973543]

108. Selkoe DJ. Alzheimer's disease: genes, proteins, and therapy. Physiol Rev. 2001; 81:741-66. [PubMed: 11274343]

109. Schenk D, Barbour R, Dunn W, Gordon G, Grajeda H, et al. Immunization with amyloid- $\beta$ attenuates Alzheimer-disease-like pathology in the PDAPP mouse. Nature. 1999; 400:173-77. [PubMed: 10408445]

110. Ferreiro E, Resende R, Costa R, Oliveira CR, Pereira CM. An endoplasmic-reticulum-specific apoptotic pathway is involved in prion and amyloid- $\beta$ peptides neurotoxicity. Neurobiol Dis. 2006; 23:669-78. [PubMed: 16844381]

111. Kadowaki H, Nishitoh H, Urano F, Sadamitsu C, Matsuzawa A, et al. Amyloid $\beta$ induces neuronal cell death through ROS-mediated ASK1 activation. Cell Death Differ. 2005; 12:19-24. [PubMed: 15592360]

112. Koge D, Schomburg R, Schurmann T, Reimertz C, Konig HG, et al. The amyloid precursor protein protects PC12 cells against endoplasmic reticulum stress-induced apoptosis. J Neurochem. 2003; 87:248-56. [PubMed: 12969271]

113. Esposito L, Gan L, Yu GQ, Essrich C, Mucke L. Intracellularly generated amyloid- $\beta$ peptide counteracts the antiapoptotic function of its precursor protein and primes proapoptotic pathways for activation by other insults in neuroblastoma cells. J Neurochem. 2004; 91:1260-74. [PubMed: 15584903]

114. Koo EH, Kopan R. Potential role of presenilin-regulated signaling pathways in sporadic neurodegeneration. Nat Med. 2004; 10(Suppl):S26-33. [PubMed: 15272268]

115. Tu H, Nelson O, Bezprozvanny A, Wang Z, Lee SF, et al. Presenilins form ER $\mathrm{Ca}^{2+}$ leak channels, a function disrupted by familial Alzheimer's disease-linked mutations. Cell. 2006; 126:981-93. [PubMed: 16959576]

116. Tandon A, Fraser P. The presenilins. Genome Biol. 2002; 3:3014-20.

117. Leissring MA, Akbari Y, Fanger CM, Cahalan MD, Mattson MP, et al. Capacitative calcium entry deficits and elevated luminal calcium content in mutant presenilin-1 knockin mice. J Cell Biol. 2000; 149:793-98. [PubMed: 10811821]

118. Yoo AS, Cheng I, Chung S, Grenfell TZ, Lee H, et al. Presenilin-mediated modulation of capacitative calcium entry. Neuron. 2000; 27:561-72. [PubMed: 11055438]

119. Lytton J, Westlin M, Hanley MR. Thapsigargin inhibits the sarcoplasmic or endoplasmic reticulum Ca-ATPase family of calcium pumps. J Biol Chem. 1991; 266:17067-71. [PubMed: 1832668] 
120. Bailly-Maitre B, Fondevila C, Kaldas F, Droin N, Luciano F, et al. Cytoprotective gene bi-1 is required for intrinsic protection from endoplasmic reticulum stress and ischemia-reperfusion injury. Proc Natl Acad Sci USA. 2006; 103:2809-14. [PubMed: 16478805]

121. Koumenis C, Naczki C, Koritzinsky M, Rastani S, Diehl A, et al. Regulation of protein synthesis by hypoxia via activation of the endoplasmic reticulum kinase PERK and phosphorylation of the translation initiation factor eIF2a. Mol Cell Biol. 2002; 22:7405-16. [PubMed: 12370288]

122. Bi M, Naczki C, Koritzinsky M, Fels D, Blais J, et al. ER stress-regulated translation increases tolerance to extreme hypoxia and promotes tumor growth. EMBO J. 2005; 24:3470-81. [PubMed: 16148948]

123. Koumenis C. ER stress, hypoxia tolerance and tumor progression. Curr Mol Med. 2006; 6:55-69. [PubMed: 16472113]

124. Blais JD, Addison CL, Edge R, Falls T, Zhao H, et al. Perk-dependent translational regulation promotes tumor cell adaptation and angiogenesis in response to hypoxic stress. Mol Cell Biol. 2006; 26:9517-32. [PubMed: 17030613]

125. Arnal M, Solary E, Brunet-Lecomte P, Lizard-Nacol S. Expression of the gadd153 gene in normal and tumor breast tissues by a sensitive RT-PCR method. Int J Mol Med. 1999; 4:545-48. [PubMed: 10534579]

126. Forus A, Florenes VA, Maelandsmo GM, Fodstad O, Myklebost O. The pro-tooncogene CHOP/ GADD153, involved in growth arrest and DNA damage response, is amplified in a subset of human sarcomas. Cancer Genet Cytogenet. 1994; 78:165-71. [PubMed: 7828148]

127. Southwood CM, Garbern J, Jiang W, Gow A. The unfolded protein response modulates disease severity in Pelizaeus-Merzbacher disease. Neuron. 2002; 36:585-96. [PubMed: 12441049]

128. Mayerhofer T, Kodym R. Gadd153 restores resistance to radiation-induced apoptosis after thiol depletion. Biochem Biophys Res Commun. 2003; 310:115-20. [PubMed: 14511657]

129. Romero-Ramirez L, Cao H, Nelson D, Hammond E, Lee AH, et al. XBP1 is essential for survival under hypoxic conditions and is required for tumor growth. Cancer Res. 2004; 64:5943-47. [PubMed: 15342372]

130. Jamora C, Dennert G, Lee AS. Inhibition of tumor progression by suppression of stress protein GRP78/BiP induction in fibrosarcoma B/C10ME. Proc Natl Acad Sci USA. 1996; 93:7690-94. [PubMed: 8755537]

131. Pluquet O, Qu LK, Baltzis D, Koromilas AE. Endoplasmic reticulum stress accelerates p53 degradation by the cooperative actions of $\mathrm{Hdm} 2$ and glycogen synthase kinase $3 \beta$. Mol Cell Biol. 2005; 25:9392-405. [PubMed: 16227590]

132. Reimold AM, Iwakoshi NN, Manis J, Vallabhajosyula P, Szomolanyi-Tsuda E, et al. Plasma cell differentiation requires the transcription factor XBP-1. Nature. 2001; 412:300-7. [PubMed: 11460154]

133. Zhang K, Wong HN, Song B, Miller CN, Scheuner D, et al. The unfolded protein response sensor IRE1a is required at 2 distinct steps in B cell lymphopoiesis. J Clin Invest. 2005; 115:268-81. [PubMed: 15690081] 133a Carrasco DR, Sukhdeo K, Protopopova M, Sinha R, Enos M, et al. The differentiation and stress response factor XBP-1 drives multiple myeloma pathogenesis. Cancer Cell. 2007; 11:349-60. [PubMed: 17418411]

134. Richardson PG, Sonneveld P, Schuster MW, Irwin D, Stadtmauer EA, et al. Bortezomib or highdose dexamethasone for relapsed multiple myeloma. N Engl J Med. 2005; 352:2487-98. [PubMed: 15958804]

135. Teicher BA, Ara G, Herbst R, Palombella VJ, Adams J. The proteasome inhibitor PS-341 in cancer therapy. Clin Cancer Res. 1999; 5:2638-45. [PubMed: 10499643]

136. Lee AH, Iwakoshi NN, Anderson KC, Glimcher LH. Proteasome inhibitors disrupt the unfolded protein response in myelomacells. Proc Natl Acad Sci USA. 2003; 100:9946-51. [PubMed: 12902539]

137. Obeng EA, Carlson LM, Gutman DM, Harrington WJ Jr, Lee KP, et al. Proteasome inhibitors induce a terminal unfolded protein response in multiple myeloma cells. Blood. 2006; 107:490716. [PubMed: 16507771] 
138. Jiang HY, Wek RC. Phosphorylation of the a-subunit of the eukaryotic initiation factor-2 (eIF2a) reduces protein synthesis and enhances apoptosis in response to proteasome inhibition. J Biol Chem. 2005; 280:14189-202. [PubMed: 15684420]

139. Nawrocki ST, Carew JS, Pino MS, Highshaw RA, Dunner K Jr, et al. Bortezomib sensitizes pancreatic cancer cells to endoplasmic reticulum stress-mediated apoptosis. Cancer Res. 2005; 65:11658-66. [PubMed: 16357177]

140. Gray MD, Mann M, Nitiss JL, Hendershot LM. Activation of the UPR is necessary and sufficient for reducing topoisomerase IIa protein levels and decreasing sensitivity to topoisomerase targeted drugs. Mol Pharmacol. 2005; 68:1699-707. [PubMed: 16141312]

141. Reddy RK, Mao C, Baumeister P, Austin RC, Kaufman RJ, et al. Endoplasmic reticulum chaperone protein GRP78 protects cells from apoptosis induced by topoisomerase inhibitors: role of ATP binding site in suppression of caspase-7 activation. J Biol Chem. 2003; 278:20915-24. [PubMed: 12665508]

142. Carew JS, Nawrocki ST, Krupnik YV, Dunner K Jr, McConkey DJ, et al. Targeting endoplasmic reticulum protein transport: a novel strategy to kill malignant $\mathrm{B}$ cells and overcome fludarabine resistance in CLL. Blood. 2006; 107:222-31. [PubMed: 16144803]

143. Fabian Z, Csatary CM, Szeberenyi J, Csatary LK. p53-Independent endoplasmic reticulum stressmediated cytotoxicity of a Newcastle disease virus strain in tumor cell lines. J Virol. 2007; 81:2817-30. [PubMed: 17215292]

144. Shen J, Hughes C, Chao C, Cai J, Bartels C, et al. Coinduction of glucose-regulated proteins and doxorubicin resistance in Chinese hamster cells. Proc Natl Acad Sci USA. 1987; 84:3278-82. [PubMed: 3106964]

145. Tomida A, Yun J, Tsuruo T. Glucose-regulated stresses induce resistance to camp-tothecin in human cancer cells. Int J Cancer. 1996; 68:391-96. [PubMed: 8903483]

146. Chatterjee S, Hirota H, Belfi CA, Berger SJ, Berger NA. Hypersensitivity to DNA cross-linking agents associated with up-regulation of glucose-regulated stress protein GRP78. Cancer Res. 1997; 57:5112-16. [PubMed: 9371511]

147. Mandic A, Hansson J, Linder S, Shoshan MC. Cisplatin induces endoplasmic reticulum stress and nucleus-independent apoptotic signaling. J Biol Chem. 2003; 278:9100-6. [PubMed: 12509415]

148. Dong D, Ko B, Baumeister P, Swenson S, Costa F, et al. Vascular targeting and antiangiogenesis agents induce drug resistance effector GRP78 within the tumor microenvironment. Cancer Res. 2005; 65:5785-91. [PubMed: 15994954]

149. Kerkela R, Grazette L, Yacobi R, Iliescu C, Patten R, et al. Cardiotoxicity of the cancer therapeutic agent imatinib mesylate. Nat Med. 2006; 12:908-16. [PubMed: 16862153]

150. Oda Y, Okada T, Yoshida H, Kaufman RJ, Nagata K, et al. Derlin-2 and Derlin-3 are regulated by the mammalian unfolded protein response and are required for ER-associated degradation. $\mathrm{J}$ Cell Biol. 2006; 172:383-93. [PubMed: 16449189]

\section{Glossary}

$\begin{array}{ll}\text { ER } & \text { endoplasmic reticulum } \\ \text { UPR } & \text { unfolded protein response } \\ \text { eIF2a } & \text { eukaryotic initiation factor } 2 a \\ \text { DM } & \text { diabetes mellitus } \\ \text { HSV } & \text { herpes simplex virus } \\ \text { HCV } & \text { hepatitis C virus } \\ \text { HBV } & \text { hepatitis B virus } \\ \text { RP } & \text { retinitis pigmentosa } \\ \text { AD } & \text { Alzheimer's disease }\end{array}$


MM multiple myeloma 


\section{Summary Points}

1. The ER is a membrane-enclosed organelle present in all eukaryotic cells that serves to fold proteins destined for secretion or membrane insertion, synthesizes lipids and sterols, and stores calcium.

2. The UPR consists of molecular signal transduction pathways that detect disturbances in the ER, such as misfolded proteins, and that determine whether a cell survives or dies in response to the stress.

3. UPR protective signaling results from the enhancement of ER protein-folding capacity, degradation of misfolded ER proteins, and attenuation of translation. UPR proapoptotic signaling is thought to involve the production of the CHOP transcription factor, activation of the ASK1 and JNK kinases, and prolonged inhibition of protein synthesis.

4. Loss of UPR protective signaling may underlie the cell death seen in heritable forms of diabetes and neurodegeneration that cause ER stress.

5. Tumor cells and viruses may co-opt UPR signaling pathways to promote their growth and replication. 


\section{Future Issues}

1. How are the protective and proapoptotic outputs of the UPR integrated after ER stress, to determine whether the cell lives or dies?

2. How does the UPR respond to physiologic ER stresses that an organism encounters routinely, and how does this response differ from the UPR in disease states?

3. What are the cell-type- and tissue-specific functions of the UPR that allow for the different needs of each specialized cell type in a multicellular organism?

4. Can individual UPR signaling pathways be selectively activated, and if so how and under what circumstances?

5. Can artificial manipulation of the UPR treat disease, either by decreasing ER stress to reduce cell death or by increasing ER stress to block cellular or viral proliferation? 


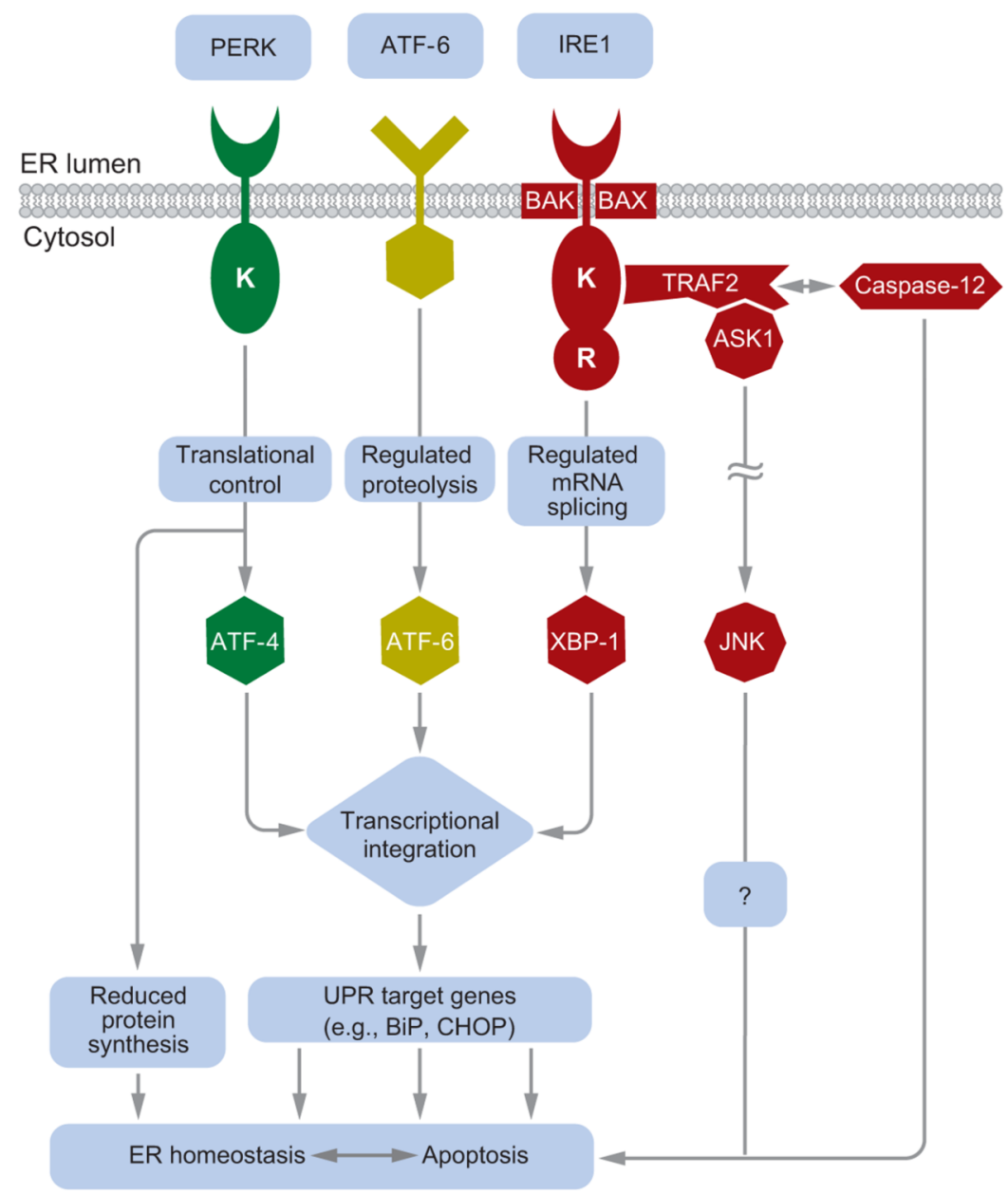

Figure 1.

A schematic of mammalian unfolded protein response (UPR) signaling. IRE1, PERK, and ATF-6 proteins reside at the ER membrane. In response to ER stress, they initiate a cascade of signal transduction outputs that control cell survival or death. Figure adapted with permission from Reference 1 . 




Figure 2.

Human immunodeficiency virus particles in an intracytoplasmic vesicle of an infected macrophage. The arrow points to a nascent budding virion. Each virion particle is enclosed in an envelope, which is composed of proteins and lipids synthesized in the ER; thus, there is increased load on the ER in cells infected by enveloped viruses. 


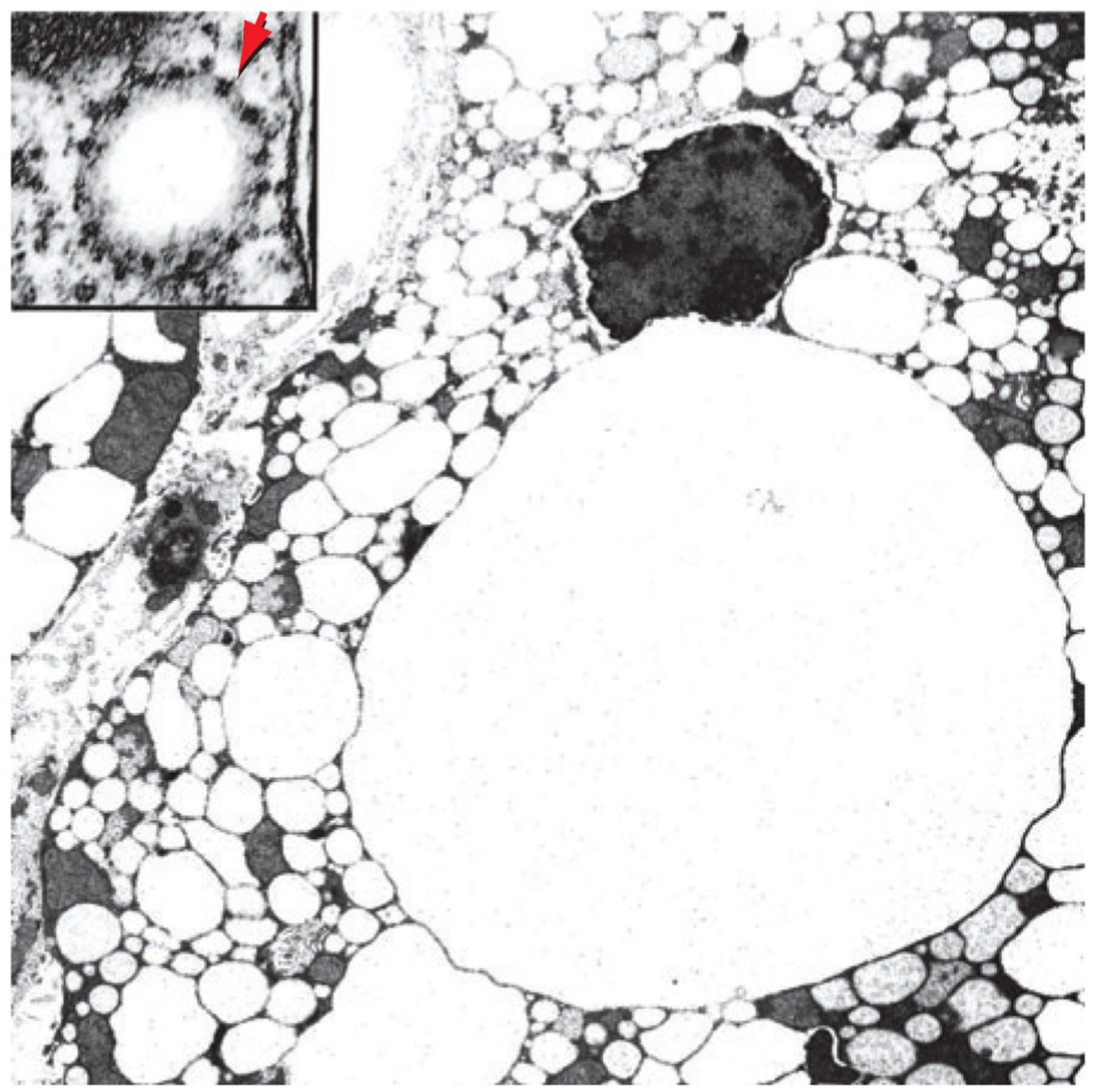

Figure 3.

Grossly enlarged ER-derived vesicles in a murine hepatocyte expressing the hepatitis B virus large surface protein. The inset shows a high-power view of an early vesicle, revealing ribosomes studding the external surface (arrow) and hence confirming that these vesicles represent dilated ER. 


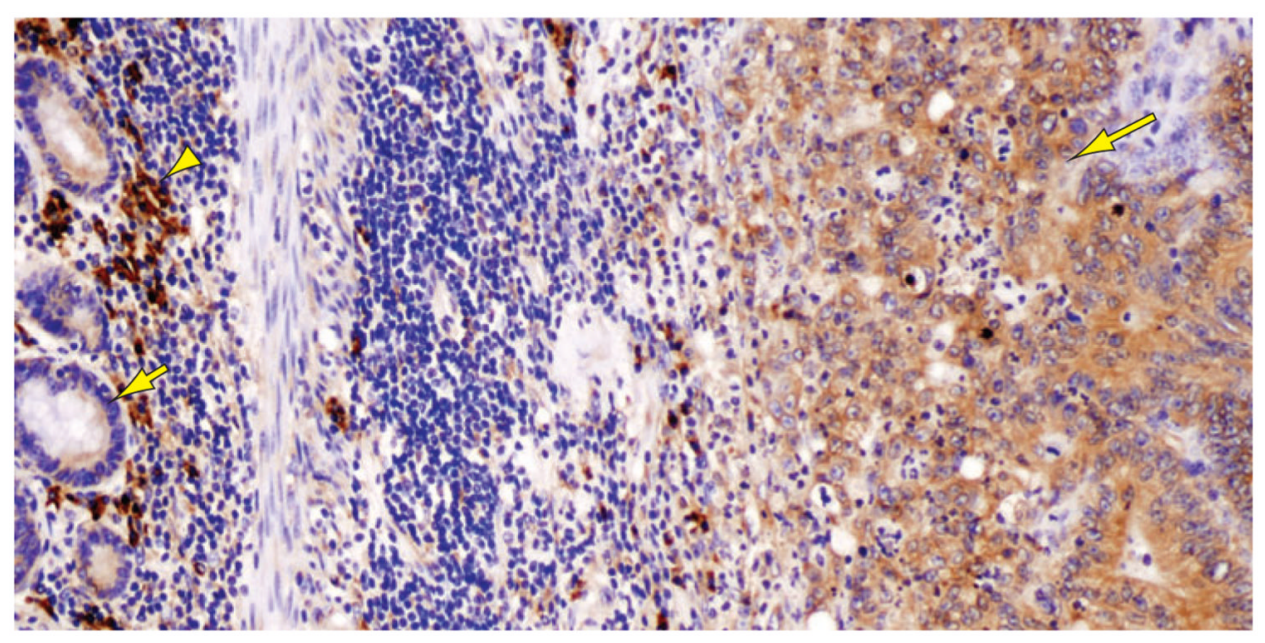

Figure 4.

Colon carcinoma cells (right, long arrow) show strong staining for GRP78 (also termed $\mathrm{BiP}$ ), an ER chaperone induced by ER stress. Note the much weaker staining of surrounding normal enterocytes (left, short arrow). The intensely stained inflammatory cells in the background (arrowhead) are plasma cells. 


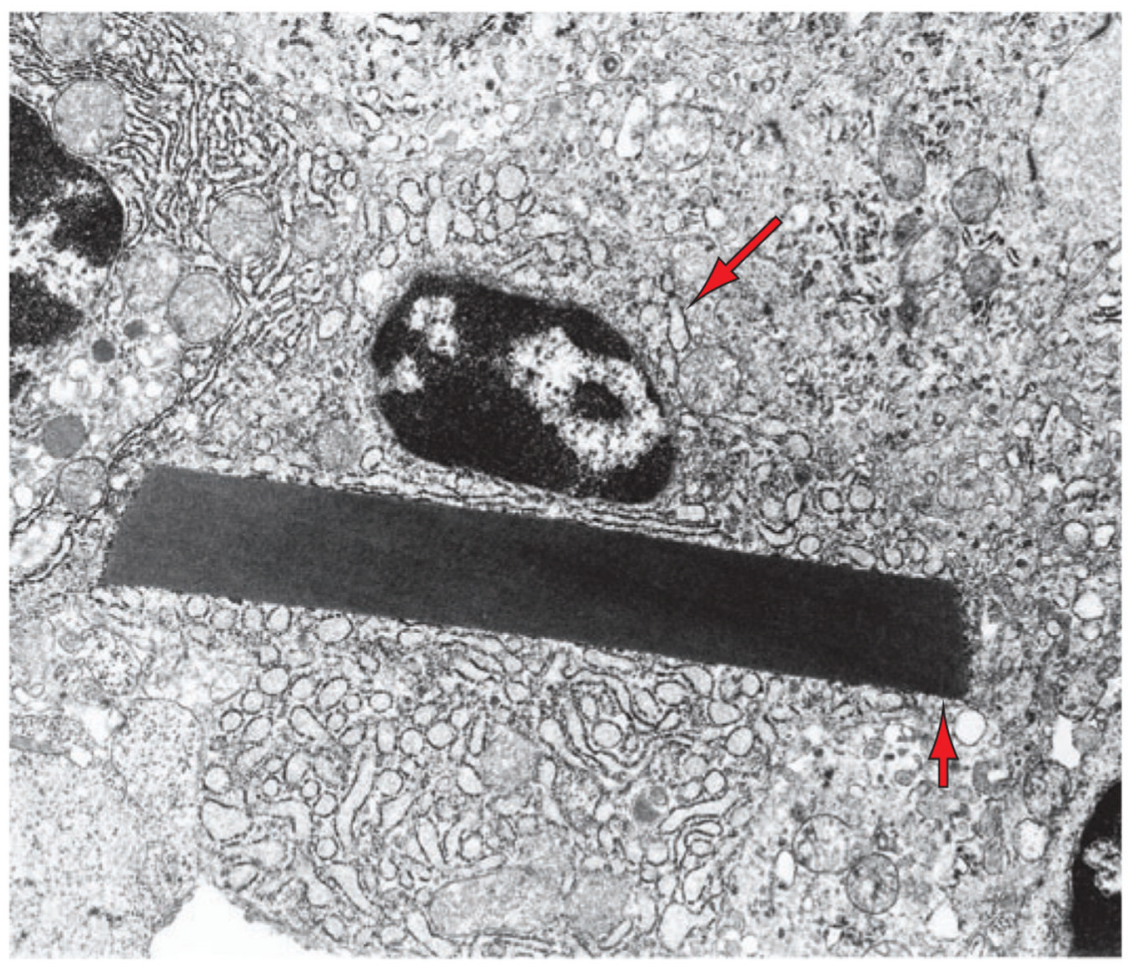

Figure 5.

A multiple myeloma cell showing dilated ER (one cisterna is indicated by the long arrow) containing proteinaceous material and a large crystal (short arrow), representing immunoglobulin molecules synthesized by this cell. 
Table 1

Modulation of chemotherapeutic efficacy by UPR activity

\begin{tabular}{llll}
\hline Agent & Mechanism of action & UPR & Reference(s) \\
\hline Etoposide & Topoisomerase inhibitor & Antagonizes & $(140)$ \\
Doxorubicin & Topoisomerase inhibitor & Antagonizes & $(140,144)$ \\
Camptothecin & Topoisomerase inhibitor & Antagonizes & $(145)$ \\
Cisplatin & DNA/protein cross-linker & Synergizes & $(146,147)$ \\
Melphalan & DNA/protein cross-linker & Synergizes & $(146)$ \\
BCNU & DNA/protein cross-linker & Synergizes & $(146)$ \\
Bortezomib (Velcade) & Proteasome inhibitor & Inhibits UPR? & $(136)$ \\
& & Activates PERK & $(137)$ \\
& & Activates GCN2 & $(138)$ \\
Combretastatin A4 & Antivascular & Induces GRP78 & $(148)$ \\
Contortrostatin & Anti-angiogenesis & Induces GRP78 & $(148)$ \\
Imatinib (Gleevec) & BCR-Abl kinase inhibitor & Induces UPR & $(149)$ \\
\hline
\end{tabular}

